\title{
Metabolic consequences of microRNA-122 inhibition in rainbow trout, Oncorhynchus mykiss
}

\author{
Jan A Mennigen ${ }^{1}$, Christopher J Martyniuk ${ }^{2}$, Iban Seiliez ${ }^{1}$, Stéphane Panserat ${ }^{1}$ and Sandrine Skiba-Cassy ${ }^{1 *}$
}

\begin{abstract}
Background: MicroRNAs (miRNAs) are small regulatory molecules which post-transcriptionally regulate mRNA stability and translation. Several microRNAs have received attention due to their role as key metabolic regulators. In spite of the high evolutionary conservation of several miRNAs, the role of miRNAs in lower taxa of vertebrates has not been studied with regard to metabolism. The liver-specific and highly abundant miRNA-122 is one of the most widely studied miRNA in mammals, where it has been implicated in the control of hepatic lipid metabolism. Following our identification of acute postprandial, nutritional and endocrine regulation of hepatic miRNA-122 isomiRNA expression in rainbow trout, we used complementary in silico and in vivo approaches to study the role of miRNA-122 in rainbow trout metabolism. We hypothesized that the role of miRNA-122 in regulating lipid metabolism in rainbow trout is conserved to that in mammals and that modulation of miRNA-122 function would result in altered lipid homeostasis and secondarily altered glucose homeostasis, since lipogenesis has been suggested to act as glucose sink in trout.

Results: Our results show that miRNA-122 was functionally inhibited in vivo in the liver. Postprandial glucose concentrations increased significantly in rainbow trout injected with a miRNA-122 inhibitor, and this effect correlated with decreases in hepatic FAS protein abundance, indicative of altered lipogenic potential. Additionally, miRNA-122 inhibition resulted in a 20\% decrease in plasma cholesterol concentration, an effect associated with increased expression of genes involved in cholesterol degradation and excretion.

Conclusions: Overall evidence suggests that miRNA-122 may have evolved in early vertebrates to support liver-specific metabolic functions. Nevertheless, our data also indicate that metabolic consequences of miRNA-122 inhibition may differ quantitatively between vertebrate species and that distinct direct molecular targets of miRNA-122 may mediate metabolic effects between vertebrate species, indicating that miRNA-122 - mRNA target relationships may have undergone species-specific evolutionary changes.
\end{abstract}

Keywords: Glycolysis, Lipogenesis, MicroRNA, Fish, Metabolism, Gene expression, Insulin signaling

\section{Background}

MicroRNAs (miRNAs) are a small class of non-coding RNAs, which were first described in Caenorhabditis elegans [1]. The class of miRNAs are posttranscriptional regulators that mediate their physiological effects both by target mRNA degradation and translational inhibition [2]. Following their discovery, miRNAs have been identified in all vertebrate classes [3], and some miRNAs have

\footnotetext{
* Correspondence: skiba@st.pee.inra.fr

'Institut National de la Recherche Agronomique (INRA), Nutrition,

Metabolism and Aquaculture Unit (UR1067), Saint-Pée-sur-Nivelle F-64310, France

Full list of author information is available at the end of the article
}

been found to be expressed in a tissue-specific manner [4]. In the mammalian liver, the miRNA expression profile is dominated by a single sequence, miR-122, with approximately 50000 copies per cell, representing close to $70 \%$ of the overall miRNAs species in this tissue [4]. In mammals, miRNA-122 has been shown to be implicated in the differentiation and maintenance of the hepatic phenotype [5-8], and the regulation of metabolic liver functions, especially lipid metabolism. Specifically, miRNA-122 exerts a stimulatory role in lipogenesis and cholesterol synthesis on the one hand, as well as an inhibitory effect on $\beta$-oxidation capacity on the other [9-11]. The tissue specific expression and high abundance 
of miRNA-122, as well as the comparatively large amount of mammalian data which made miRNA-122 a 'paradigm' in miRNA research [12], make this miRNA a particularly suitable target of study for comparative investigation. In rainbow trout (Oncorhynchus mykiss), miRNA-122 is specifically localized to the liver [13], where it is highly abundant [14], reflecting the situation in mammals. We have previously shown that a specific isoform of miRNA-122, omy-miRNA-122b, is postprandially regulated in rainbow trout [14], and that this regulation depends on macronutrient composition and the endocrine factor insulin [15], a key metabolic hormone. These findings led us to investigate the function of miRNA-122 in rainbow trout, which, in spite of its high degree of evolutionary conservation [16], has not been characterized functionally in lower vertebrates. Specifically, given its key implication in lipid metabolism in higher vertebrates, we investigated the hypothesis, that miRNA-122 is equally involved in the regulation of lipid metabolism in trout, and that, via modulation of lipid metabolism, it may secondarily regulate postprandial glucose metabolism in this species. Rainbow trout are carnivorous fish which are considered poor utilizers of dietary carbohydrate [17], but several lines of evidence have shown that induction of hepatic de novo lipogenesis may act as a 'glucose-sink' in rainbow trout, resulting in improved utilization of glucose. For example an improved postprandial glucose profile was observed in a 'fat line' of rainbow trout, characterized by increased expression of genes involved in de novo lipogenesis in the liver, as well as increased muscle fat content $[18,19]$. Pharmacological modulation of rainbow trout by the antidiabetic drug metformin equally resulted in improved postprandial glucose clearance, but in contrast to mammals, this effect was not correlated with a repression of hepatic gluconeogenic gene expression, but rather with an induction of hepatic lipogenic gene expression [20], providing further evidence for an involvement of hepatic de novo lipogenesis in glucose clearance in rainbow trout. Acute administration of insulin in rainbow trout resulted in increased fas gene expression, protein abundance and enzymatic activity of FAS [21], and this acute, insulinstimulated FAS activity has been shown to increase hepatic triglyceride synthesis [22], which may, in part, contribute to improved glucose utilization induced by insulin [21]. Lastly, a link between hepatic glucose utilization and lipogenesis has also been shown at the metabolite level in rainbow trout, as radioactively labeled glucose is dosedependently metabolized into triglycerides [23,24]. In order to investigate a possible role for miRNA-122 in coordinating postprandial glucose homeostasis through the modulation of lipid metabolism, we used an in vivo approach by blocking the activity of miRNA-122 using a short LNA-miRNA-122 inhibitor (LNA-122i) [25]. This approach was complemented by in silico approaches to predict potential direct mRNA targets of miR-122 in rainbow trout, as well as to predict potentially regulated pathways.

\section{Results \\ Mature miRNA-122 is highly conserved in the vertebrate lineage}

The comparison of genomic sequences between several fish species and higher vertebrates reveals complete evolutionary conservation of the mature miRNA-122 sequence in vertebrates (Figure 1). The complimentary strand, miRNA-122*, reveals an overall high conservation, however differences in nucleotides do exist among species. The loop region linking both strands does not display a high degree of sequence conservation, in line with its function as a connecting structural component in the hairpin structure (Figure 1). Precursors containing miRNA-122 sequences are present in the genomes of all vertebrate classes, but are absent from the sea lamprey (Petromyzon marinus) genome (data not shown).

\section{Predicted direct miRNA-122 target genes in rainbow trout are enriched for proliferation and differentiation processes, but not metabolism}

The predicted direct miRNA-122 target genes in rainbow trout (Additional file 1), are highly enriched for cell cycle regulation, as well as cell proliferation and differentiation processes (Figure 2). With the exception of glucose metabolism, no distinct metabolic pathways feature in the list of enriched target genes (SNEA cell process sheet, line 31; Additional file 1).

\section{Hepatic omy-miRNA-122 isomiRNAs are functionally inhibited in LNA-122i injected rainbow trout}

Expression of all hepatic omy-miRNA-122 isomiRNA sequences, mature omy-miRNA-122 $(\mathrm{df}=2 ; \quad \mathrm{F}=6.824$; $\mathrm{p}<0.01)$, omy-miRNA-122a $(\mathrm{df}=2 ; \mathrm{F}=8.708 ; \mathrm{p}<0.01)$ and omy-miRNA-122b ( $\mathrm{df}=2 ; \mathrm{F}=16.9 ; \mathrm{p}<0.01)$ was significantly inhibited by LNA-122i treatments, irrespective of dose (Figure 3A-C). Conversely, hepatic expression of omymiRNA-103 ( $\mathrm{df}=2 ; \mathrm{F}=0.041 ; \mathrm{p}>0.05)$, omy-miRNA-33 $(\mathrm{df}=2, \mathrm{~F}=1.999 ; \mathrm{p}>0.05)$ and omy-miRNA-21 $(\mathrm{df}=2$; $\mathrm{F}=1.127 ; \mathrm{p}>0.5)$ did not change significantly with LNA122i treatment (Figure 3D-F). The expression of individual in silico predicted putative direct omy-miRNA-122 targets in rainbow trout (Additional file 1) was measured to validate the functionality of omy-miRNA-122 isomiRNA inhibition (Figure 3G-I). Hepatic expression of fish-lineage specific cyp $2 k 5 \quad(\mathrm{df}=2 ; \quad \mathrm{F}=6.53$; $\mathrm{p}<0.01)$ increased significantly in fish injected with either dose of LNA-122i (Figure 3G). A significant de-repression of prostaglandin reductase 1, ptgr1 $(\mathrm{df}=2 ; \mathrm{F}=10.09 ; \mathrm{p}<0.01 ;$ Figure $3 \mathrm{H})$ was observed 
in fish injected with LNA-122i, as well as an increase in archain $1, \operatorname{arcn} 1(\mathrm{df}=2 ; \mathrm{F}=8.209 ; \mathrm{p}<0.01$; Figure 3I).

\section{Inhibition of miRNA-122 results in postprandial hyperglycemia and decreased lipid availability}

Plasma glucose concentration increased by $62 \%$ an $67 \%$, respectively with LNA-122i treatments and this increase was significant $(\mathrm{df}=2 ; \mathrm{F}=17.93 ; \mathrm{p}<0.01)$, irrespective of dose (Figure 4A). With regard to lipid metabolites, both triglyceride $(-36 \%)$ and free fatty acid concentration $(-46 \%)$ in the plasma decreased in fish treated with the higher dose of $25 \mu \mathrm{g} / \mathrm{g} \mathrm{LNA}-122 \mathrm{i}$, and both decreases were significant $(\mathrm{df}=2 ; \mathrm{F}=4.017 ; \mathrm{p}<0.05$ and $\mathrm{df}=2 ; \mathrm{F}=7.07 ; \mathrm{p}<0.01$; Figure 4B-C). The LNA-122i treatments lead to small $(-20 \%)$, but significant decreases in cholesterol $(\mathrm{df}=2$; $\mathrm{F}=3.038, \mathrm{p}<0.05$ ), which, however, did not result in significant pair-wise comparisons between individual treatment groups (Figure 4D).
Gene expression of hepatic metabolic markers is regulated by miRNA-122 inhibition Effect of omy-miRNA-122 inhibition on genes involved in hepatic glucose metabolism

The effect of miRNA-122 inhibition on the expression of genes involved in hepatic glucose metabolism, specifically glucose import, glycolysis, gluconeogenesis and glycogen metabolism was measured (Figure 5). The expression of the hepatic glucose transporter, glut2, did not change significantly with LNA-122i treatment $(\mathrm{df}=2 ; \mathrm{F}=0.15 ; \mathrm{p}>0.862$; Figure $5 \mathrm{~A})$. With regard to gene expression of components of the glycolytic pathway, a decrease in expression of glucokinase, $g k$, was observed in fish injected with LNA-122i $(\mathrm{df}=2 ; \mathrm{F}=7.025$; $\mathrm{p}<0.05$; Figure $5 \mathrm{~B}$ ), which was significantly decreased when comparing fish injected with a dose of $25 \mu \mathrm{g} / \mathrm{g}$ LNA-122i to saline-injected control fish. The expression of neither liver phosphofructokinase, l-pfk $\quad(\mathrm{df}=2$; $\mathrm{F}=0.774 ; \mathrm{p}>0.05 ;$ Figure $5 \mathrm{C}$ ), nor pyruvate kinase, $p k$ 


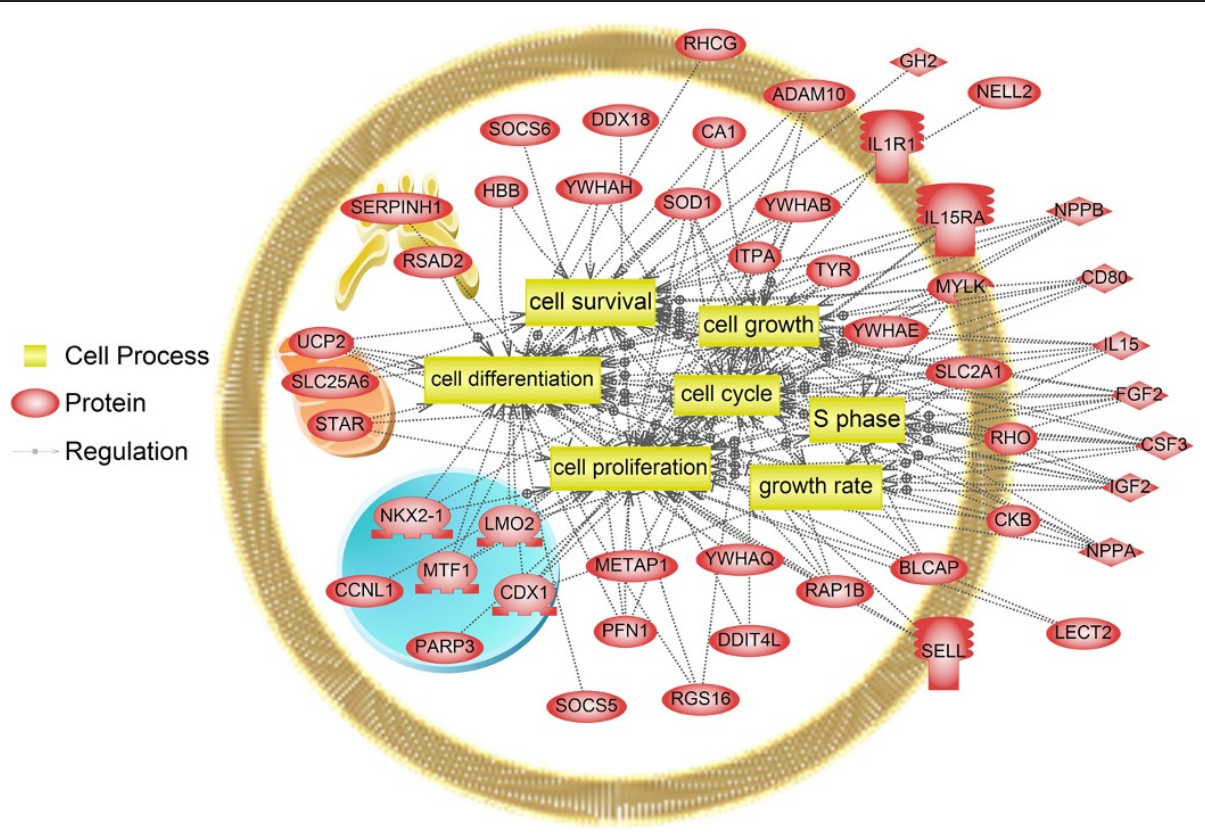

Figure 2 Rainbow trout targets were identified and their functional enrichment for specific GO terms analyzed as described in the text. A particular enrichment was noted for pathways involved in cell cycle regulation, cell proliferation and differentiation. Compared to the comprehensive identification and validation of murine targets provided by Tsai et al. [30], 11\% of rainbow trout targets were predicted to be conserved targets. All of the conserved targets (ddit/4, igf2, parp3, rtn3, serpinh1, socs6, ucp2a, s/c2a1 and adam 10) are enriched in pathways regulating cell cycle, cell proliferation and differentiation, indicating an evolutionary conservation of specific miRNA-122 target relationships that govern these processes.

$(\mathrm{df}=2 ; \quad \mathrm{F}=0.774 ; \mathrm{p}>0.05 ;$ Figure $5 \mathrm{D})$ showed any changes between treatment groups.

The expression of the gluconeogenic genes glucose6-phosphatase 1, g6pase1 $(\mathrm{df}=2 ; \mathrm{F}=1.303 ; \mathrm{p}>0.05$; Figure $5 \mathrm{E})$, fructose 1,6-bisphophatase, fbpase ( $\mathrm{df}=2$; $\mathrm{F}=1.345 ; \quad \mathrm{p}>0.05 ;$ Figure $5 \mathrm{~F}$ ), and mitochondrial phosphoenolpyruvate carboxykinase, m-pepck $(\mathrm{df}=2$; $\mathrm{F}=1.371 ; \mathrm{p}>0.05$; Figure $5 \mathrm{G}$ ), did not change between treatments. The expression of genes involved in glycogen metabolism, glycogen synthase, gys $2(\mathrm{df}=2 ; \mathrm{F}=6.01$ $\mathrm{p}<0.05$; Figure $5 \mathrm{H}$ ) increased in fish treated with either dose of LNA-122i, while glycogen phosphorylase, pyk, $(\mathrm{df}=2 ; \mathrm{F}=1.529 \mathrm{p}>0.5$; Figure $5 \mathrm{I})$, did not exhibit significant changes between treatment groups.

\section{Effect of omy-miRNA-122 inhibition on genes involved in hepatic lipid metabolism}

The effect of miRNA-122 inhibition on hepatic expression of genes involved in hepatic lipid metabolism, specifically lipogenesis, and $\beta$-oxidation, were analyzed (Figure 6). The expression of sterol regulatory binding protein 1c, srebp1c $(\mathrm{df}=2 ; \mathrm{F}=6.176 ; \mathrm{p}<0.05$; Figure $6 \mathrm{~A})$, increased significantly compared to saline control in fish injected with $25 \mu \mathrm{g} / \mathrm{g}$ LNA-122i. The expression of genes implicated in lipogenesis did not change between treatments for glucose-6-phosphate dehydrogenase, g6pdh $(\mathrm{df}=2 ; \mathrm{F}=0.153 ; \mathrm{p}>0.05 ;$ Figure $6 \mathrm{~B})$, or fatty acid synthase, fas ( $\mathrm{df}=2 ; \mathrm{F}=0.317 ; \mathrm{p}>0.05$; Figure $6 \mathrm{C})$, but the expression of acetyl-CoA-carboxylase, acc $(\mathrm{df}=2$; $F=5.07 ; p<0.05$; Figure $6 D$ ), increased significantly in LNA-122i treated fish, irrespective of the administered dose. With regard to the expression of genes implicated in fatty acid $\beta$-oxidation pathways, the expression of carnithine palomtyl transporter isoforms, cpt1a $(\mathrm{df}=2$; $\mathrm{F}=1.905 ; \mathrm{p}>0.05$; Figure $6 \mathrm{E})$, and $c p t 1 b(\mathrm{df}=2 ; \mathrm{F}=1.426$; $\mathrm{p}>0.05$; Figure $6 \mathrm{~F}$ ), did not change significantly with treatment, while expression of 3-hydroxyacyl-CoA dehydrogenase, hoad $(\mathrm{df}=2 ; \mathrm{F}=3.897 ; \quad \mathrm{p}<0.05$; Figure 6G), was significantly increased in fish injected with $12.5 \mu \mathrm{g} / \mathrm{g}$ LNA-122i compared to saline-injected control fish.

Effect of omy-miRNA-122 inhibition on genes involved in hepatic cholesterol homeostasis The expression of hepatic genes implicated in cholesterol synthesis, as well as export and degradation were investigated (Figure 7). A significant increase in sterol regulatory binding protein 2 , srebp $2(\mathrm{df}=2 ; \mathrm{F}=14.02$; $\mathrm{p}<0.01$; Figure 7A), was observed in fish treated with $25 \mu \mathrm{g} / \mathrm{g}$ LNA-122i when compared to controls. No significant changes in the gene expression of hydroxymethylglutaryl CoA synthase, hmgcs $(\mathrm{df}=2 ; \mathrm{F}=2.849$; p $>0.05$; Figure 7B), hydroxymethylglutaryl CoA reductase, $h m g c r(\mathrm{df}=2 ; \mathrm{F}=0.864 ; \mathrm{p}>0.05$; Figure $7 \mathrm{C})$ and 7-dehydrocholesterol reductase, dhcr $7 \quad(\mathrm{df}=2$; 

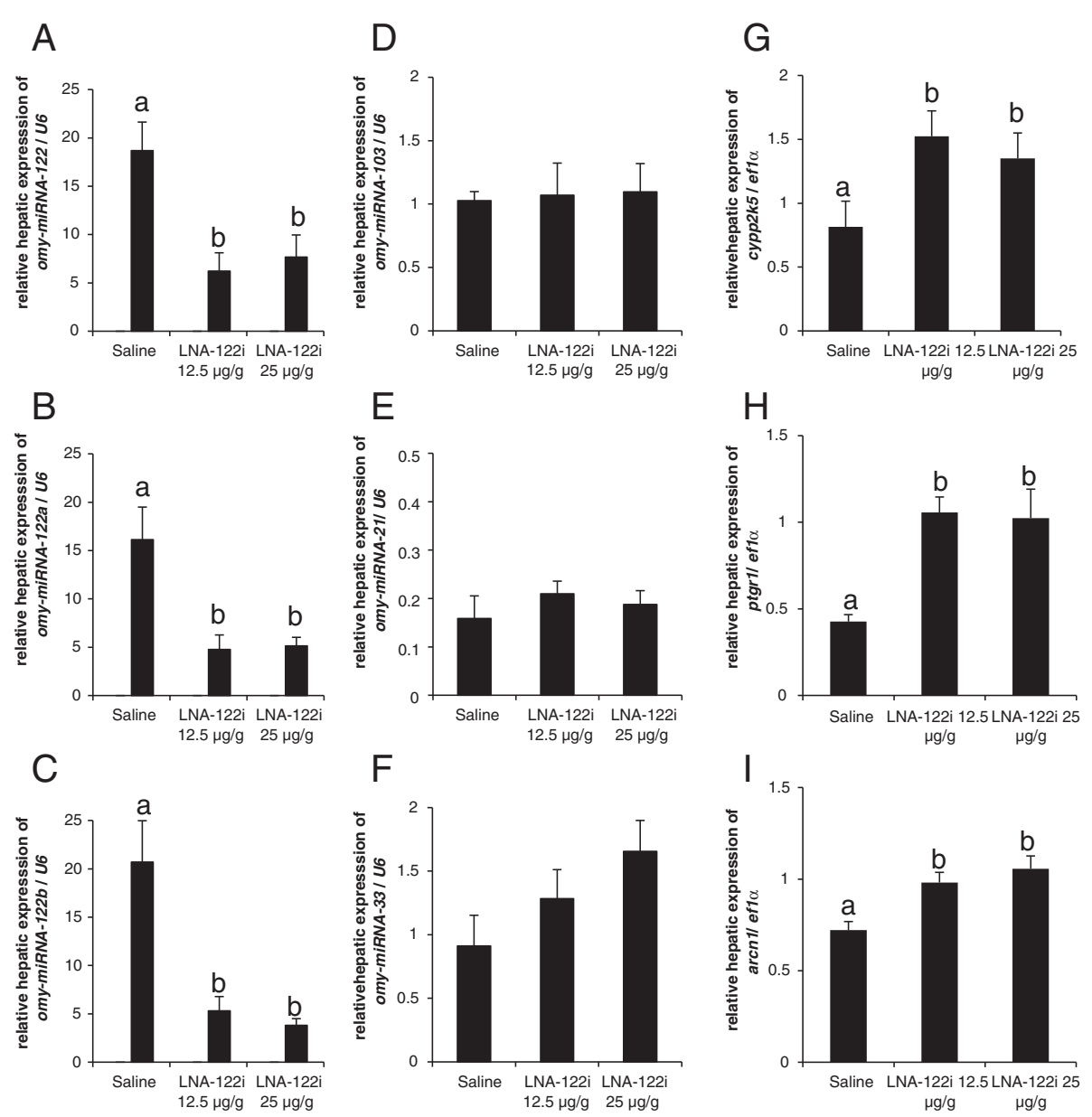

Figure 3 Effect of LNA-122i treatment on hepatic omy-miRNA-122 isomiRNA expression (A-C), expression of hepatic, non-targeted omy-miRNA species (D-F) and hepatic mRNAs predicted in silico to be targeted by omy-miRNA-122 isomiRNAs (G-I). Analyzed groups consisted of $n=6$ samples and data are depicted as mean \pm S.E.M. for each group. Data were analyzed using one-way ANOVA and differences between individual experimental groups assessed by Student-Newman-Keuls post-hoc test. Different letters indicate a significant difference $(p<0.05)$ between experimental groups.

$\mathrm{F}=0.351 ; \mathrm{p}>0.05 ;$ Figure 7D), were observed. The expression of liver receptor $\mathrm{x}, \quad \operatorname{lxr}(\mathrm{df}=2 ; \mathrm{F}=4.5$; $\mathrm{p}<0.05$ : Figure 7E), increased in LNA-122i treated fish, irrespective of dose. No changes were observed in cholesterol-7alpha-hydroxylase a, cyp7a, $(\mathrm{df}=2$; $\mathrm{F}=1.383 ; \mathrm{p}>0.05$; Figure $7 \mathrm{~F})$, while $c y p 7 b$ was increased in fish treated with $25 \mu \mathrm{g} / \mathrm{g}$ LNA-122i compared to other treatment groups $(\mathrm{df}=2 ; \mathrm{F}=8.399$; $\mathrm{p}<0.01$; Figure $7 \mathrm{~F}$ ). The expression of ATP-binding cassette sub-family $\mathrm{G}$ member $8, \operatorname{abcg8} \quad(\mathrm{df}=2$; $\mathrm{F}=1.175 ; \mathrm{p}>0.05$; Figure $7 \mathrm{G}$ ), did not change between treatment groups, while significant increases in the expression of ATP-binding cassette sub-family G member 5 , abcg5 ( $\mathrm{df}=2 ; \mathrm{F}=4.035 ; \mathrm{p}<0.05$; Figure $7 \mathrm{G})$ were found in trout injected with $25 \mu \mathrm{g} / \mathrm{g}$ LNA-122i. The expression of UDP glycosyltransferase 1 family, polypeptide A3, utg1a3 $(\mathrm{df}=2 ; \mathrm{F}=6.79 ; \mathrm{p}<0.01$;
Figure $7 \mathrm{H}$ ), increased in trout injected with either dose of LNA-122i.

\section{Effect of omy-miRNA-122 inhibition on hepatic insulin signaling}

As an important upstream regulator of postprandial metabolic gene expression in the liver, we investigated the activity of the hepatic insulin signaling pathway. The activity of the insulin pathway, as determined by the ratio phosphorylated/total protein, remained unaltered for all components investigated (Figure 8A-G). Values from the statistical analysis are presented in Table 1 . At the total protein level, a significant decrease in total mTOR protein was observed $(\mathrm{df}=2 ; \mathrm{F}=5.285 ; \mathrm{p}<0.05$; Figure $8 \mathrm{~B})$, which was significantly reduced in fish treated with $12.5 \mu \mathrm{g} / \mathrm{g}$ LNA-122i compared to saline-injected control fish. 

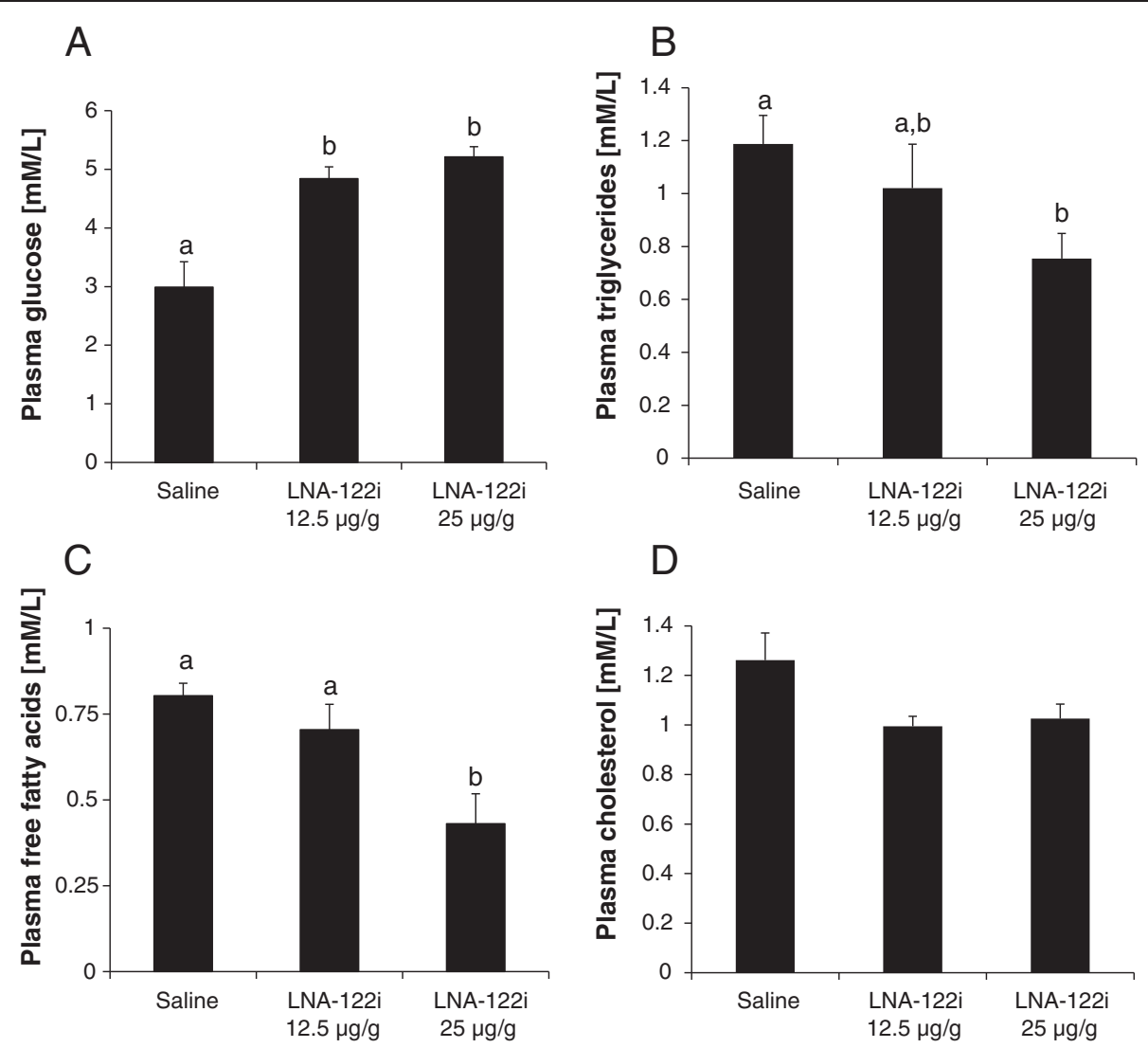

Figure 4 Effect of LNA-122i treatment on plasma concentrations of the metabolites glucose (A), triglycerides (B), free fatty acids (C) and cholesterol (D). Analyzed groups consisted of $n=6$ samples and data are depicted as mean \pm S.E.M. for each group. Data were analyzed using one-way ANOVA and differences between individual experimental groups assessed by Student-Newman-Keuls post-hoc test. Different letters indicate a significant difference $(p<0.05)$ between experimental groups.

Effect of omy-miRNA-122 inhibition on hepatic protein abundance of key metabolic enzymes

Protein abundance of glucokinase, GK (Figure 9A), did not change significantly between treatment groups, while that of fatty acid synthase, FAS (Figure 9B), significantly decreased in fish injected with either dose of LNA-122i, compared to saline-injected control fish. Values from the statistical analysis are presented in Table 1.

\section{Discussion}

The comparison of miRNA-122 across several vertebrate species from genomic sequences reveals a complete conservation of miRNA-122 and high conservation of miRNA-122* across vertebrate classes, while nucleotides forming the loop between both pairing strands in the pre-miRNA-122 molecule appear to be under less selective pressure. The fact that miRNA-122 is absent from the lamprey genome, but present in the elephant shark, an elasmobranch, places the acquisition of miRNA-122 at the base of the vertebrate lineage evolution between 560 and 530 MYA [26]. Interestingly, and in contrast to other fish species, two loci for pre-miRNA-122 containing two completely conserved mature miRNA-122 sequences are present in the rainbow trout genome. This likely reflects tetraploidization and re-diploidization that occurred in the salmonid lineage 25-100 MYA [26], as two sequences were also identified in the genome of another salmonid species, the Atlantic salmon. However, the functional consequences of this duplication remain unknown, but provide for interesting future studies, especially given the relative rarity of miRNA duplication events in teleost fish genomes [27]. Being liver-specific and highly abundant in both rainbow trout $[13,14]$ and mammals [4], the postulated hypothesis that miRNA-122 evolved along with the vertebrate liver [16] is tempting. Interestingly, no pre-miRNA-122 coding sequence was found in the lamprey genome. While a liver is already present in lampreys, which are believed to have separated from the vertebrate lineage 560 MYA [26], its phenotype is plastic across developmental stages, as it undergoes biliary atresia and lamprey develop a compensatory ability of the intestine to synthesize bile acids [28]. 

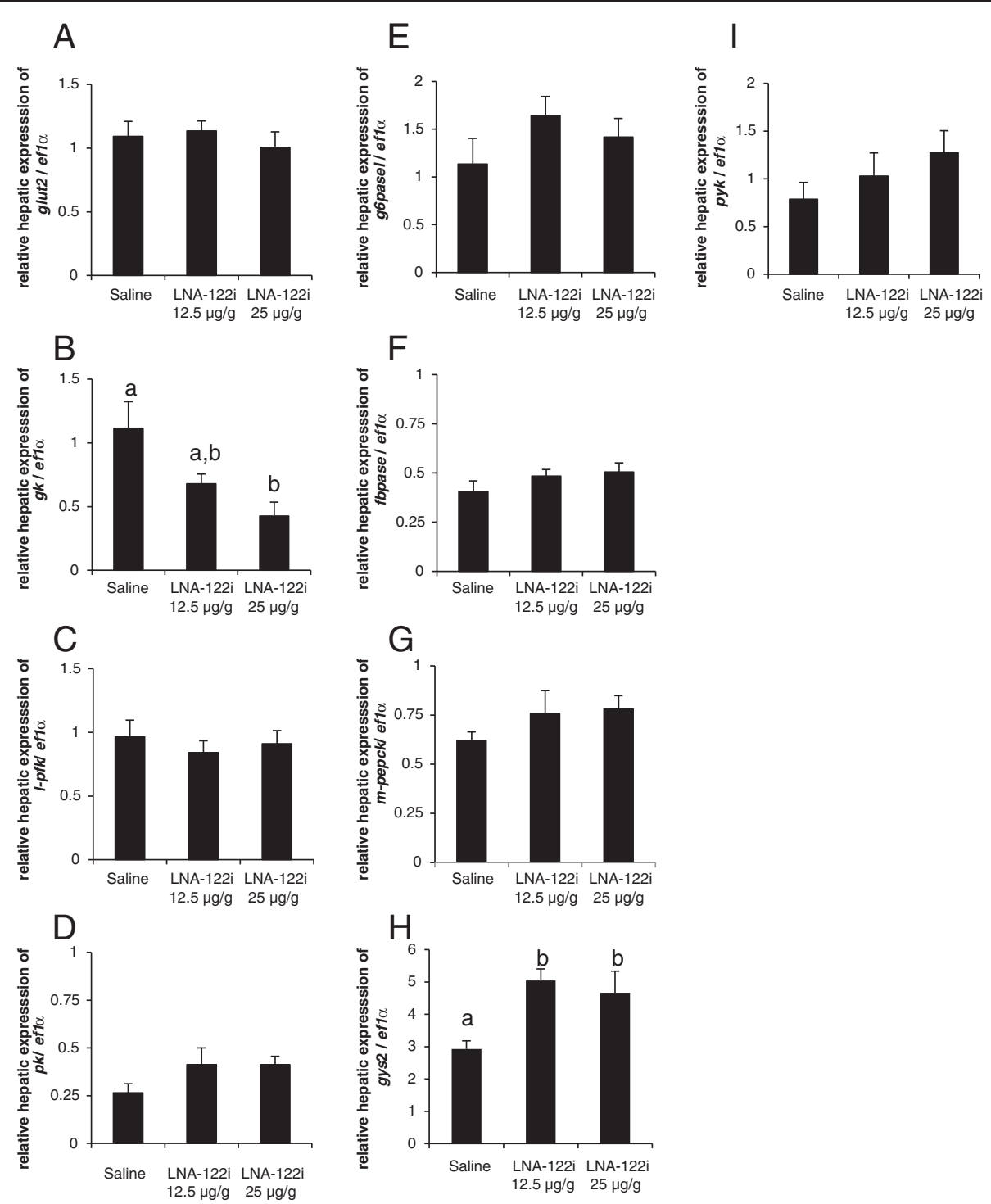

Figure 5 Effect of LNA-122i treatment on hepatic expression of genes implicated in glucose metabolism. Expression of genes involved in glucose transport (A), glycolysis (B-D), gluconeogenesis (E-G) and glycogen metabolism (H-I) was analyzed analyzed using one-way ANOVA and differences between individual experimental groups assessed by Student-Newman-Keuls post-hoc test. Analyzed groups consisted of $\mathrm{n}=6$ samples and data are depicted as mean \pm S.E.M. for each group. Different letters indicate a significant difference $(p<0.05)$ between experimental groups.

Since $m i R N A-122$ has been shown to play a role in hepatocyte and biliary tract differentiation in zebrafish [5,29], the evolution of miRNA-122 may indeed have contributed to promote a stable hepatic phenotype seen in vertebrates. Our in silico target prediction revealed several specific trout mRNA targets of miRNA-122. Compared to a comprehensive list of predicted and validated targets from miRNA-122 KO mice [30], a moderate $11 \%$ of predicted targets were conserved targets between both species. In spite of the moderate conservation of direct miRNA-122 target genes between trout and mice, the identified conserved targets, in addition to newly identified trout-specific targets, are enriched for functional annotations indicative of cell proliferation and differentiation processes. Therefore, the functional prediction of miRNA-122 target genes in rainbow trout is consistent with the development and maintenance of a hepatic phenotype, similar to the experimentally validated function of miRNA-122 in mammals [6-8], and more recently, zebrafish [5,29]. This finding is further corroborated by the identification of rainbow trout mRNA targets of miRNA-122 that are extra-hepatic and tissue specific, such as, for example, gastric chitinase, otholith matrix molecule 64, muscle-expressed myosin 

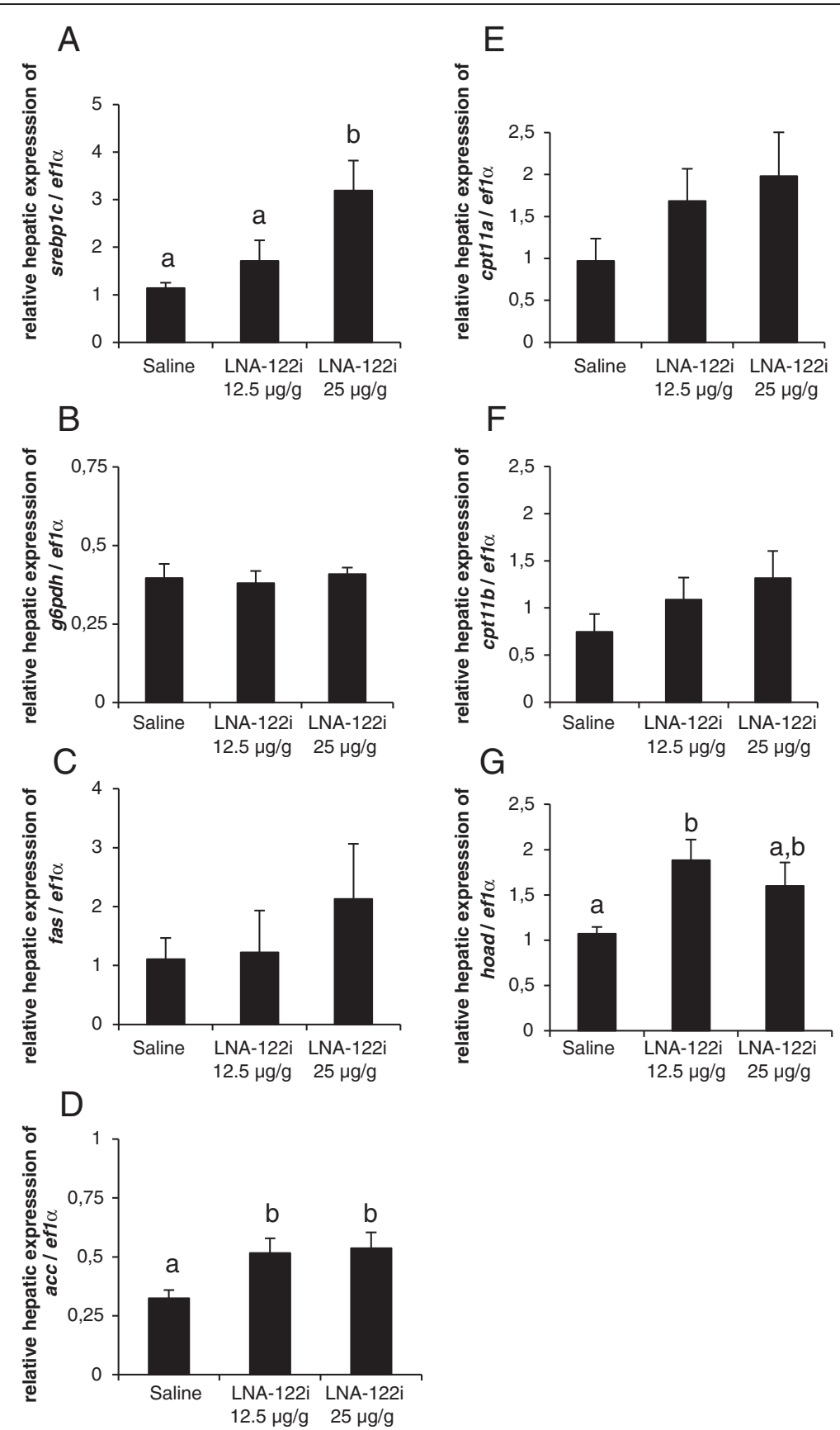

Figure 6 Effect of LNA-122i treatment on hepatic expression of genes implicated in lipid metabolism. Expression of genes with roles in lipogenesis (A-D) and $\beta$-oxidation of fatty acids (E-G) was analyzed using one-way ANOVA and differences between individual experimental groups assessed by Student-Newman-Keuls post-hoc test. Analyzed groups consisted of $n=6$ samples and data are depicted as mean \pm S.E.M. for each group. Different letters indicate a significant difference $(p<0.05)$ between experimental groups.

light chain, blood cell-expressed hemoglobin, and retinaexpressed rhodopsin (Additional file 1). This is in good agreement with the postulated role of the tissue-specific miRNA-122 which may in part maintain the hepatic phenotype by repressing extra-hepatic tissue-specific transcripts [31]. With the exception of glucose metabolism (Additional file 1), little enrichment was observed for predicted rainbow trout miRNA-122 target genes with a role in metabolic pathways. This is consistent with the finding that metabolic effects of miRNA-122 may be related to 'indirect' miRNA-122 target genes, whose expression is modulated indirectly and as a consequence of alteration of gene expression of direct target genes. For example, several miRNA-122 inhibition 


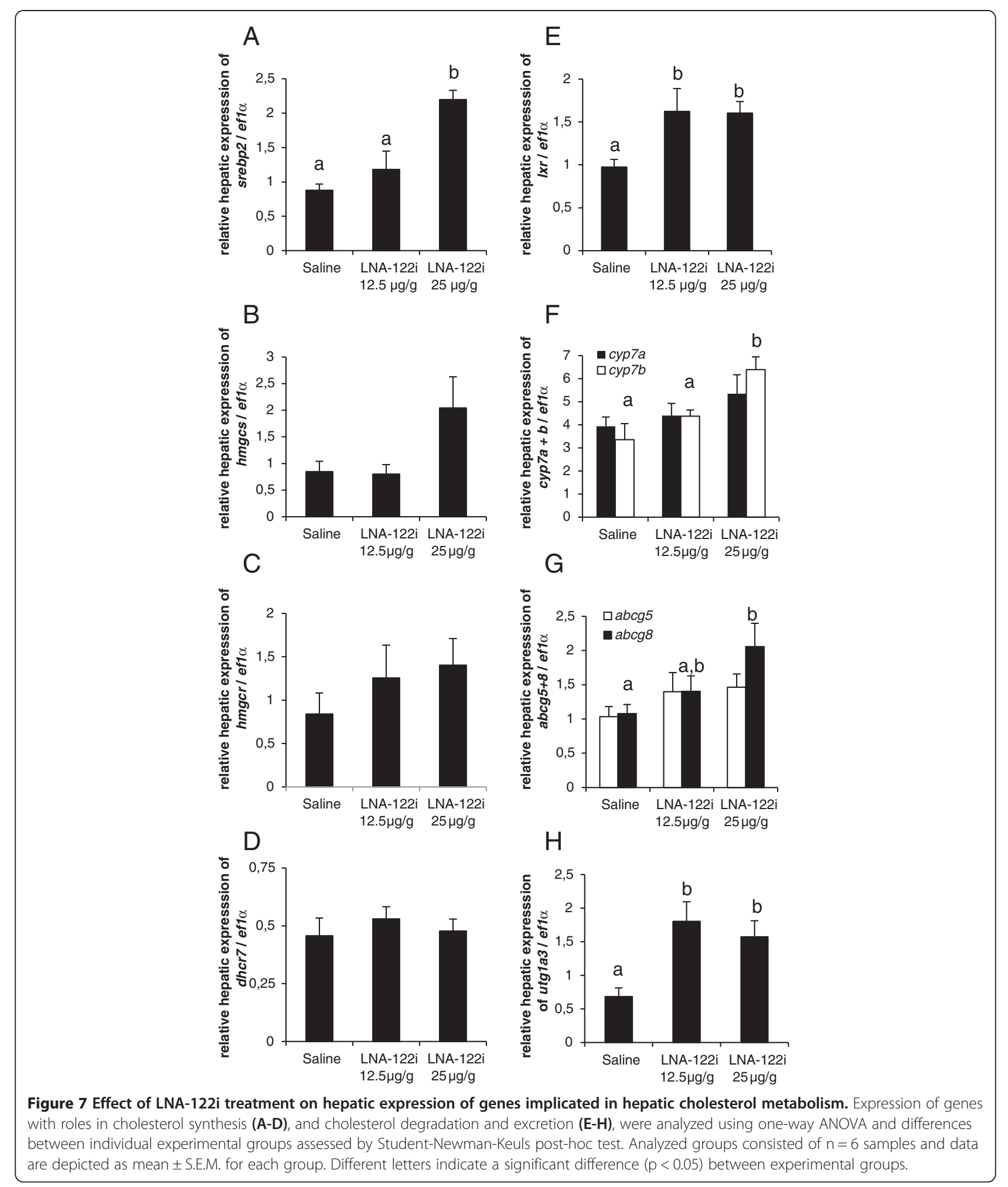

studies in mammalian model systems have linked the observed decrease in cholesterol and triglycerides in these species to decreased expression of cholesterol and fatty acid synthesis genes [9-11], without establishing a link to direct miRNA-122 target genes. Therefore, in addition to validating individual predicted direct miRNA-122 target gene expression to assess functional efficiency of miRNA-122 inhibition in trout, we focused 


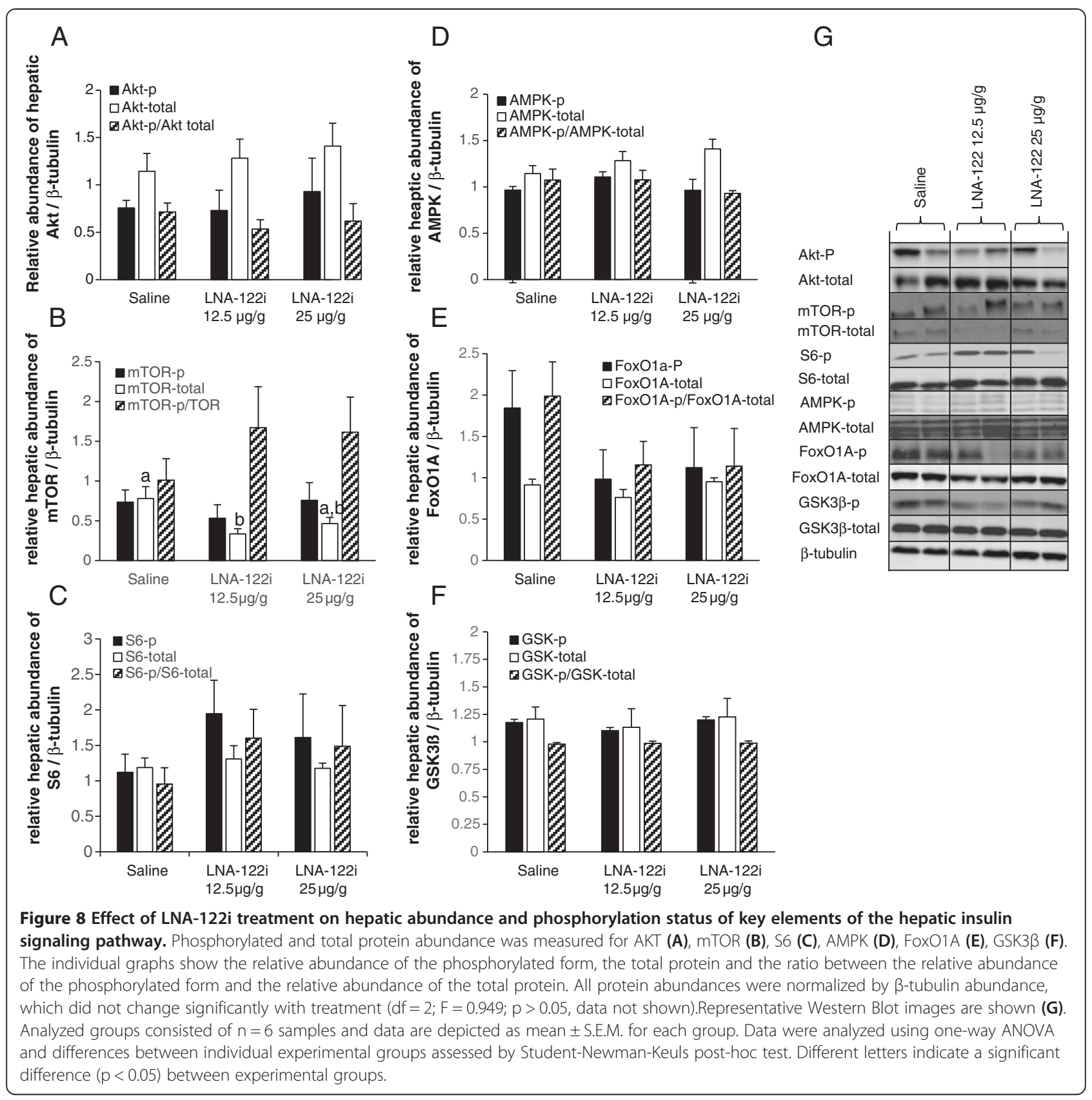

on analyzing the expression of non-target markers of key hepatic metabolic pathways to elucidate the underlying (indirect) molecular mechanisms for the observed metabolic consequences in vivo. This approach is especially suitable in studying metabolic pathways, which, albeit not exclusively, are highly regulated at the level of transcription [32]. It should be noted, however, that 3' UTR annotation of trout mRNAs remains incomplete, and that future studies may identify additional (metabolic) miRNA-122 target genes in rainbow trout.
Efficient miRNA-122 isomiRNA inhibition in rainbow trout in vivo

Inhibition of miRNA-122 was confirmed by real-time RTPCR, which has been shown to be a monitoring technique to assess efficient hepatic miRNA-122 inhibition in vivo $[10,11,33]$. Given the fact that multiple isomiRNAs of miRNA-122, likely resulting from posttranscriptional modifications, had initially been described in both rainbow trout as in mammals $[13,34]$, we aimed to inhibit the expression of not only the conserved mature omy-miRNA-122, but 
Table 1 Statistical analysis associated with the Western Blot measurements of (phosphorylated) proteins involved in the insulin signaling pathway and metabolic proteins shown in Figure 9 and 10

\begin{tabular}{|c|c|}
\hline Protein & One-way ANOVA \\
\hline AKT-P & $d f=2 ; F=0.130 ; p>0.05$ \\
\hline AKT-total & $d f=2 ; F=0.399 ; p>0.05$ \\
\hline AKT-P/AKT-total & $d f=2 ; F=0.461 ; p>0.05$ \\
\hline mTOR-P & $d f=2 ; F=0.444 ; p>0.05$ \\
\hline mTOR-total & $d f=2 ; F=5.285 ; p<0.05^{*}$ \\
\hline mTOR-P/mTOR-total & $d f=2 ; F=0.445 ; p>0.05$ \\
\hline S6-P & $d f=2 ; F=0.786 ; p>0.05$ \\
\hline S6-total & $d f=2 ; F=0.278 ; p>0.05$ \\
\hline S6-P/S6-total & $d f=2 ; F=0.653 ; p>0.05$ \\
\hline AMPKa-P & $d f=2 ; F=1.070 ; p>0.05$ \\
\hline AMPKa-total & $d f=2 ; F=0.464 ; p>0.05$ \\
\hline AMPKa-P/AMPKa-total & $d f=2 ; F=0.643 ; p>0.05$ \\
\hline FoxO1-P & $d f=2 ; F=1.497 ; p>0.05$ \\
\hline FoxO1-total & $d f=2 ; F=0.974 ; p>0.05$ \\
\hline FoxO1-P/FoxO1-total & $d f=2 ; F=1.779 ; p>0.05$ \\
\hline GSK3 $\beta-P$ & $d f=2 ; F=0.145 ; p>0.05$ \\
\hline GSK3a $+\beta$ total & $d f=2 ; F=0.339 ; p>0.05$ \\
\hline GSK3 $\beta-P / G S K 3 a+\beta$ total & $d f=2 ; F=0.145 ; p>0.05$ \\
\hline GK & $d f=2 ; F=1.652 ; p>0.05$ \\
\hline FAS & $d f=2 ; F=14.2 ; p<0.001^{* *}$ \\
\hline$\beta$-tubulin & $d f=2 ; F=0.409 ; p>0.05$ \\
\hline
\end{tabular}

The asterisk symbol $\left(^{*}\right)$ indicates a significant difference at $\mathrm{p}<0.05$, while two asterisks $\left({ }^{* *}\right)$ denote a significant difference at $p<0.001$ ).

also of the identified trout isomiRNAs, specifically omymiRNA-122a and omy-miRNA-122b. The miRNA-122 isomiRNAs share a common miRNA-122 seed sequence, hence all are considered functional. However, possible divergent biological functions for the isomiRNAs are currently debated $[34,35]$. With regard to the study of regulatory effects of miRNA-122 in rainbow trout, the fact that all three isoforms were found to be inhibited by LNA-122i treatment ensures that no uninhibited functional isoforms of miRNA-122 can compensate for the inhibited mature form. In order to exclude potential effects of the LNA-122i treatment on the canonical miRNA pathway, we assessed the expression of non-targeted omy-miRNA-103, omy$m i R N A-21$ and omy-miRNA-33, and found no significant changes in expression between treatment groups. Lastly, as an index of functional inhibition of miRNA-122, we validated an expected de-repression of in silico predicted, rainbow trout-specific targets of miRNA-122, including the fish specific cytochrome cyp $2 k 5$, the prostaglandin reductase ptgr1, and archain arcn1. For all three genes, a significant de-repression was confirmed, irrespective of the dose administered. Overall, our study reveals the feasibility of silencing approaches in fish, an area comparatively understudied $[36,37]$, in spite of its great potential for comparative physiology.

Inhibition of miRNA-122 results in postprandial hyperglycemia and decreased availability of lipids in the plasma

The dose-independent $>60 \%$ increase in blood glucose found in trout subjected to miRNA-122 inhibition has not been described in mice, where miRNA-122 inhibition resulted only in slight, but non-significant, trends for increases in plasma glucose [9]. Interestingly, in an acute glucose tolerance test in miRNA-122 knock-out mice, Tsai and colleagues [30] observed small, but statistically significant increases in acute postprandial (60$120 \mathrm{~min}$ ) measurements of blood glucose after glucose injection, emphasizing the importance of sampling time when analyzing particular metabolic endpoints. Nevertheless the increase appears to be stronger in rainbow trout than in mammalian model systems, especially given the fact that miRNA-122 knock-out mice generally
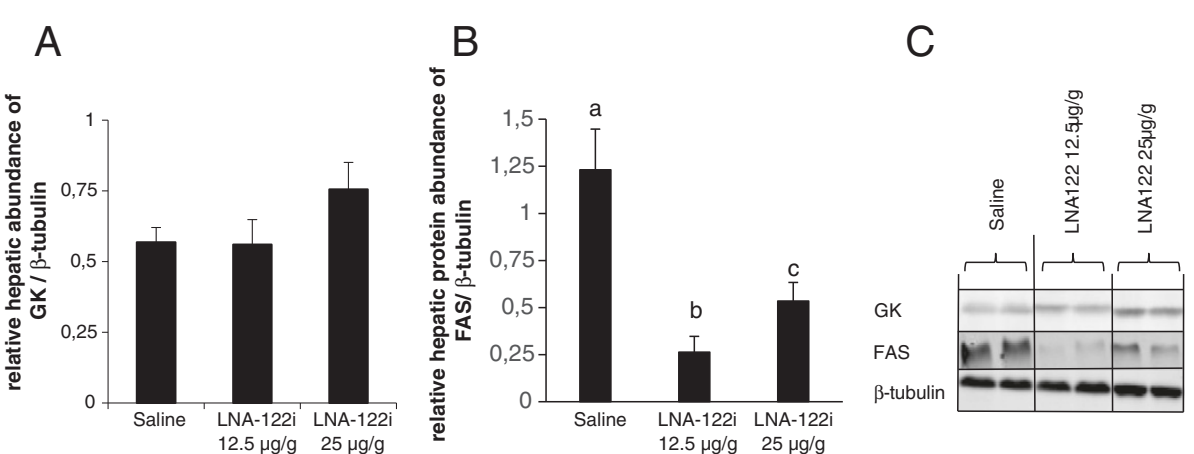

Figure 9 Effect of LNA-122i treatment on hepatic protein abundance of key factors in hepatic glucose and lipid metabolism: Densitometry results for Glucokinase, GK (A) and fatty acid synthase, FAS (B) are shown, as well as representative Western Blot images (C). Analyzed groups consisted of $n=6$ samples and data are depicted as mean \pm S.E.M. for each group. Data were analyzed using one-way ANOVA and differences between individual experimental groups assessed by Student-Newman-Keuls post-hoc test. Different letters indicate a significant difference $(p<0.05)$ between experimental groups. 


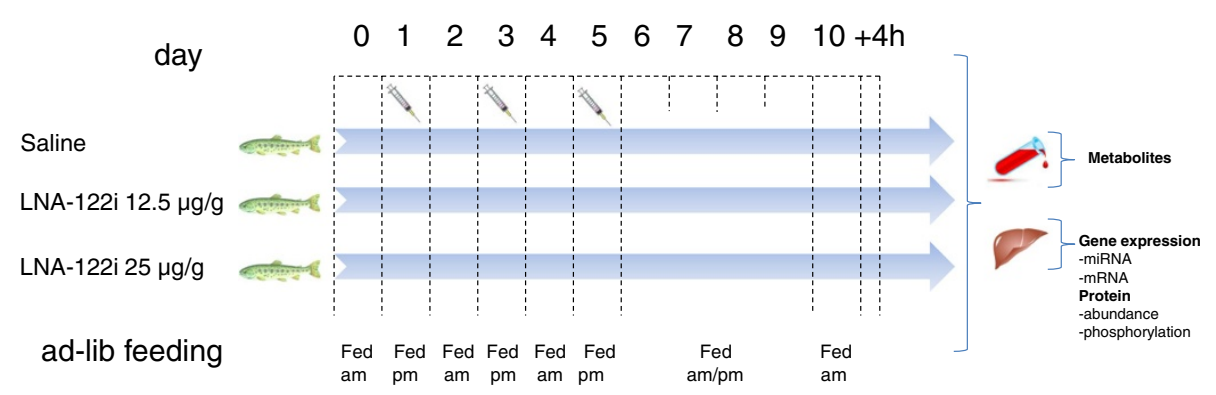

Figure 10 Schematic representation of the experimental design for the in vivo study of metabolic effects of LNA-122i. Detailed

explanations are provided in the text. Samples analyzed in this study stem from postprandial fish fed $4 \mathrm{~h}$ before sacrifice.

suffer from more pronounced metabolic consequences compared to mice injected with a LNA-122i which display reversible metabolic effects [11,30]. With regard to plasma triglyceride concentration, the significant $>30 \%$ decrease in plasma triglyceride concentration in trout treated with $25 \mu \mathrm{g} / \mathrm{g}$ LNA-122i is similar to a significant $40 \%$ decrease observed in mice treated with the same dose of LNA-122i and subjected to a similar injection protocol [10]. Similarly, recent studies on miRNA-122 knock-out models detected significant, persistent decreases in serum triglycerides [30]. The concentration of free fatty acids in trout plasma paralleled the observed plasma concentration of triglycerides. The plasma concentration of free fatty acids decreased significantly $(<40 \%)$ in trout injected with the higher dose of $25 \mu \mathrm{g} / \mathrm{g}$ of LNA-122i. This is in contrast to findings in mammalian model systems, where only a very slight, nonsignificant decrease of free fatty acids in mice injected with miRNA-122 inhibitors have been found [9]. A decrease of $20 \%$ in plasma cholesterol concentration was observed in trout injected with LNA-122i, irrespective of the dose administered. This decrease in plasma cholesterol concentrations was significant but slight, and posthoc comparisons did not resolve differences between individually compared treatment groups. In mammalian miRNA-122 inhibition studies [9-11], as well as recent mammalian knock-out models [30,38], reductions of cholesterol between $20-50 \%$ have been observed, making it the most consistently observed metabolic effect of miRNA-122 inhibition in mammals. In all cases, the effects on plasma cholesterol are long lasting but reversible [11] and interestingly, similar to our study, an increase in dose does not lead to further decrease in plasma cholesterol concentration, suggesting a saturation effect [10]. While the metabolic effects of miRNA122 inhibition in trout are largely in line with the effects reported in the mammalian literature, the quantitative nature of these effects appears to differ slightly between trout and mammalian model systems. Nevertheless, these differences should be interpreted with caution, since the measured metabolites are subject to acute, but temporally different, postprandial changes in mammals [39] as in trout [40]. Hence, the fact that our study was specifically designed to target acute postprandial changes is in contrast to most published literature using mammalian model systems, where animals were either fasted, or the information of the feeding times was not indicated [9-11]. These differences in experimental design may have contributed to different measurements of plasma metabolite concentrations.

\section{Characterization of potential hepatic molecular mechanisms underlying the metabolic phenotype} In order to establish potential underlying molecular mechanisms in the development of the observed metabolic phenotype in rainbow trout experiencing miRNA122 inhibition, we investigated specific metabolic markers in the hepatic tissue.

\section{Postprandial hyperglycemia in trout with miRNA-122 inhibition decreases hepatic gk expression and FAS protein levels}

To investigate molecular mechanisms underlying the observed postprandial hyperglycemia, we investigated hepatic gene expression for transcripts implicated in the hepatic intermediary metabolism of glucose and lipids, as transcriptional regulation of these pathways plays an important role in regulating systemic glucose homeostasis [32]. Specifically, we investigated hepatic genes with a role in (1) glucose utilization (glucose uptake, glycolysis and glycogenesis) and (2) hepatic glucose production (gluconeogenesis and glycogenolysis). Additionally, to test our hypothesis that miRNA-122 alters glucose metabolism by regulating hepatic de novo lipogenesis, we quantified responses for genes involved in lipogenesis and fatty acid oxidation. The effect of miRNA-122 inhibition on hepatic protein abundance of key enzymes of both, the glycolytic (GK), and lipogenic pathway (FAS) were measured, to account for potential effects of miRNA-122 at the protein level in these pathways.

With respect to hepatic glucose catabolism, we identified a significant decrease in $g k$ mRNA expression in fish 
Table 2 Sequences and conditions for new primers used in SYBR Green real-time RT-PCR assays

\begin{tabular}{|c|c|c|c|c|c|}
\hline Gene & Forward primer $\left(5^{\prime} 3^{\prime}\right)$ & Reverse primer $\left(3^{\prime} 5^{\prime}\right)$ & $\begin{array}{l}\mathrm{Tm} \\
\left({ }^{\circ} \mathrm{C}\right) \\
\end{array}$ & $\begin{array}{l}\text { Gene bank or SIGENAE } \\
\text { accession number }\end{array}$ & Amplicon size (bp) \\
\hline omy-miRNA-122 & TGGAGTGTGACAATGGTGTTGT & Poly T Primer (Invitrogen) & 60 & - & - \\
\hline cyp2k5 & CTCACACCACCAGCCAAGAC & CGTCAGCAGAGGTAACACATCAG & 60 & NM_001124742 & 76 \\
\hline ptgr1 & CAGTGATTGTGGATGGAGGAG & CCTTGATCTTGGCGATCTGT & 60 & NM_001124634 & 238 \\
\hline $\operatorname{arcn} 1$ & AGCCTCACTTGTGGGAGAGA & CTTGTCACCGTTGTTGATGG & 60 & NM_001164069 & 119 \\
\hline Gs & AAGATATGGAGGCGGAGAGG & GATCTCAAGGACCAGGGTTG & 60 & BX299627.p.om.8 & 152 \\
\hline Pygl & AACCGACACCTCCACTTCACC & ССTGCATCTTCСTCСАТСTC & 60 & BX882218.p.om.8 & 296 \\
\hline srebp2 & TAGGCCCCAAAGGGATAAG & TCAGACACGACGAGCACAA & 60 & BX859204.p.om.8 & 161 \\
\hline Hmgcs & AGTGGCAAAGAGAGGGTGTG & TTCTGGTTGGAGACGAGGAG & 60 & CX251971.p.om.8 & 298 \\
\hline Hmger & GAACGGTGAATGTGCTGTGT & GACCATTTGGGAGCTTGTGT & 60 & AB218825.p.om.8 & 216 \\
\hline dhcr7 & GTAACCCACCAGACCCAAGA & ССTCTCCTATGCAGCCAAAC & 60 & CA376644.p.om.8 & 289 \\
\hline сур7а & ACGTCCGAGTGGCTAAAGAG & GGTCAAAGTGGAGCATCTGG & 60 & AB675933 & 111 \\
\hline cyp7b & ACAGAGACCTCACCTTCACCA & GATCTCCCTTCCTCACTCCA & 60 & F6VG15V01BFI5C.p.om.8 & 171 \\
\hline$a b c g 5$ & CACCGACATGGAGACAGAAA & GACAGATGGAAGGGGATGAA & 60 & CU073172.p.om.8 & 268 \\
\hline$a b c g 8$ & GATACCAGGGTTCCAGAGCA & CCAGAAACAGAGGGACCAGA & 60 & FYV3OTN01BVHON.p.om.8 & 159 \\
\hline utgla3 & CCACCAGCAAGACAGTCTCA & CAACAGCACAGTGGCTGACT & 60 & F6VG15V01BF6CZ.p.om.8 & 216 \\
\hline
\end{tabular}

Gene bank accession number (www.ncbi.nlm.nih.gov/genbank) are provided when available. For the remaining sequences, accession numbers from the trout EST database SIGENAE (www.sigenae.org) are provided. Additional primer sequences have been previously published and can be found in sources cited in the text.

when injected with $25 \mu \mathrm{g} / \mathrm{g}$ LNA-122i. Glucokinase belongs to the hexokinase family and is highly expressed in the liver; its specific properties allow the hepatic influx of glucose across the physiological range of blood glucose concentration [41]. Functionally, glucokinase therefore represents an important node in glucose metabolism, channeling postprandial hepatic glucose flux towards oxidative pathways, but also towards energy storage in the form of glycogen deposition and de novo lipid synthesis, the latter of which is subsequently exported to adipose tissue for storage. It can therefore be considered the first step of lipogenesis. Liver specific knock-out [42] or overexpression [43,44] of $g k$ in mammalian model systems provide unequivocal evidence that hepatic GK regulates blood glucose homeostasis by limiting hepatic glucose utilization for glycogen synthesis and the de novo lipogenic pathway. In rainbow trout, $g k$ expression is, as in mammals, mainly hepatic, and is reduced by fasting and induced by (carbohydrate) feeding [45]. Interestingly, in trout, unlike in mammals, carbohydrates are capable of stimulating $g k$ expression independently of insulin [46,47], and thus $g k$ is considered a glucose sensor $[46,47]$. The diminished levels of $g k$ mRNA may be indicative of a reduced postprandial glucose sensing capacity in trout experiencing miRNA122 inhibition. However, the extrapolation of functional consequences, as seen in mammalian knock-out models is difficult based on our data, since, at the protein level, hepatic GK abundance did not change between control and LNA-122i injected fish. Further time course studies are required to address whether the decreased postprandial induction of the glucosensor $g k$ results in temporally delayed changes in GK protein concentration. With regard to glycogen synthesis, a paradoxical increase in mRNA abundance of hepatic glycogen synthase, the rate-limiting enzyme in glycogen deposition, was observed in trout injected with either dose of LNA-122i. While these data do not correspond to the observed increase in plasma glucose, the fact that fish were sampled $5 \mathrm{~d}$ following the last injection of the LNA-122i may reflect that the induction of gys 2 represents a counter-regulatory response to cope with hyperglycemia. The observed change in indicators of glycogen metabolism, particularly in the form of increased gys 2 expression, is in contrast to findings from a recent mouse miRNA-122 knock-out model, where mild postprandial hyperglycemia was correlated with decreased hepatic glycogen storage and decreased protein abundance and activity of glycogen synthase [30]. Unfortunately, due to the limited hepatic size in juvenile fish, we were unable to use the samples to measure hepatic glycogen content directly in addition to other hepatic measurements, therefore the current results should be interpreted with caution. Transcript markers of hepatic anabolic pathways of glucose metabolism, specifically at the level of gluconeogenesis and glycogenolysis, did not change with LNA-122i treatment, indicating that the observed postprandial hyperglycemia in LNA-122i treated rainbow trout is, at the level of gene expression, not related to hepatic glucose production or liberation.

In terms of lipid metabolism, miRNA-122 inhibition in trout resulted in significant increases in the expression 
of genes involved in lipogenesis $(s r e b p 1 c, a c c)$. The expression pattern observed for lipogenic genes is in contrast to mammalian studies, where comparable miRNA-122 inhibition results in decreased expression of lipogenic genes, which correlate with decreased lipogenesis. Similarly, the observed results are contrary to correlative evidence from postprandial studies in rainbow trout [14], in which a positive correlation between omy-miRNA-122b and the lipogenic genes srebplc has been described. Whether these differences represent distinct, species-specific actions of miRNA-122 in trout and mammalian models in the form of a direct regulation of srebp1c or acc by miRNA-122 in trout can currently not be predicted, as 3'UTR sequences for either gene are currently unavailable. Differences in the experimental protocol may also play a role in the observed changes at the level of gene expression, especially given that the metabolic consequences on plasma lipid metabolites are largely consistent between trout and mammals. While most studies in mammalian models investigated gene expression shortly after the last injection $[9,10]$, our study design measured effects several days following the last injection. In line with this, the only transcriptomic time-course study of miRNA-122 inhibition in the liver of mice [11], revealed an initial inhibition of the expression of the lipogenic gene srebp1c, which however were not detected $1 \mathrm{wk}$ following the treatment, in spite of persisting, albeit less severe, miRNA-122 inhibition and metabolic effects. The increased expression of acc, the rate limiting enzyme in lipogenesis with both doses of LNA$122 \mathrm{i}$, may represent an adaptive response to cope with increased glycemic load, similar to the effect observed for gys2. Whether these mechanisms do indeed represent physiological responses to maintain homeostasis in plasma metabolites is not known, but may be delineated by following a time-course study, and through aforementioned advances in annotation of 3'UTR sequences in trout. While we did not observe changes in fas gene expression between treatment groups, hepatic FAS abundance was significantly inhibited at the protein level, similar to miRNA-122 KO mice [30]. While this is indicative of reduced hepatic lipogenesis that is also observed in mammalian model species [10], the current result does not support the previously observed post-prandial and insulin-mediated co-regulation of miRNA-122 and fas [15]. The discrepancy between gene expression and protein abundance data suggests that, in spite of the previously observed co-regulation of specific miRNA122 isomiRNAs and fas in trout $[14,15]$ and the observed concurrent decrease of fas in miRNA-122 inhibited mammalian models [11], fas, at the level of gene expression, may not be an indirect target of miRNA-122 in rainbow trout. Alternatively, the LNA122i induced decrease of FAS, but not fas gene expression, may reflect temporally anterior changes in fas expression/translation in unfed fish, which based on the estimated half-life of FAS in mammals [48], may still manifest themselves postprandially. As previously noted, the limited amount of biological material in juvenile fish prevented the direct measurement of hepatic lipid contents, and without direct measurements of hepatic lipid concentrations in addition to the measured plasma lipid concentrations, the current interpretations on hepatic lipogenesis are inferred from hepatic gene expression and protein data, as well as plasma metabolite data. Therefore these data should be interpreted cautiously.

\section{Inhibition of omy-miRNA-122 does not alter hepatic insulin signaling}

Since miRNA-122 has been shown to stimulate hepatic insulin signaling in mammals [49], and since a postprandial coordination of glycolysis and lipogenesis is mediated by the insulin pathway in rainbow trout [50], as in mammals [51], we investigated the possible upstream involvement of the insulin pathway in the observed metabolic effects of miRNA-122 inhibition in rainbow trout. In trout, similar to the situation in mammals, it has recently been shown that inhibition of mTOR, a key node in the insulin pathway, results in decreased expression of hepatic $g k$ and fas [50]. Given our hypothesis that miRNA-122 may control glucose homeostasis through regulation of glycolytic flux and subsequent de novo lipogenesis in rainbow trout, we analyzed the postprandial activity of hepatic insulin pathway with a particular focus on the mTOR node. Indeed, recent evidence from studies investigating miRNA-122 function in mammalian model systems points to a stimulatory role for miRNA122 on the activity of the insulin pathway, and mTOR in particular. Depletion of miRNA-122 in Hep2 cells resulted in tyrosine phosphatase $1 \mathrm{~B}$ induction and subsequently, reduced activity of the insulin pathway, including a reduction in mTOR phosphorylation status [49]. Inhibition of miRNA-122 equally resulted in increased phosphorylation status of the metabolic sensor AMPK $\alpha$ [10], which, in its phosphorylated form, acts to inhibit mTOR signaling [52]. In our study, miRNA122 inhibition resulted in no notable differences in the phosphorylation status of any component of the hepatic insulin signaling pathway, indicating that the metabolic effects observed in trout injected with LNA-122i are not mediated by acute, postprandial alteration of hepatic insulin signaling. Interestingly, the only detected change in any of the components of the insulin pathway was noted in the total protein abundance of mTOR, which decreased significantly in trout injected with $12.5 \mu \mathrm{g} / \mathrm{g}$ LNA-122i. This regulation however did not alter the activity of the mTOR kinase, since the ratio of mTOR phosphorylated form/total form did not change 
significantly between treatment groups and since the same index was unaffected for S6, a downstream target of mTOR. While the physiological relevance of a decrease in total hepatic mTOR protein abundance is difficult to interpret, it may limit the maximum capacity of downstream events such as lipogenesis. Whether such decreases in total mTOR abundance can become rate-limiting under physiological conditions, however, is currently not known.

\section{Genes involved in reverse cholesterol transport are increased in miRNA-122-inhibited fish}

The inhibition of miRNA-122 resulted in slightly, but significantly, reduced plasma cholesterol levels, mirroring findings from numerous studies in mammalian models [9-11,30]. In contrast to the identification of a decrease in cholesterol biosynthesis genes in these studies, which were considered to be a likely cause for the observed decrease in plasma cholesterol, genes implicated in cholesterol synthesis either increased (srebp2) or did not change their expression (dhr7; hcgr; hcgs) in response to $m i R N A-122$ inhibition in trout. Conversely, $m i R N A-122$ inhibition resulted in an increase in genes implicated in cholesterol sensing $(l x r)$, and excretion (abca5, utg1a3). Interestingly, the expression of $l x r$, a nuclear receptor that serves as a rheostat for systemic cholesterol homeostasis [53-55], was increased in LNA-122i injected trout, irrespective of dose. In the liver, LXR is activated by its endogenous ligand oxysterol, which is generated in conditions of high intracellular concentrations of cholesterol [56]. In a positive feedback loop, activated LXR stimulates its own expression, which is the case in both mammals [57] and rainbow trout [58]. In mammals, hepatic LXR regulates several effectors involved in excreting cholesterol directly into the bile, or metabolizing cholesterol into bile acids, which are subsequently conjugated and excreted via bile secretion [54]. Given the conservation of several targets of LXR between mammals and fish $[59,60]$, we investigated the potential induction of these downstream targets to provide further evidence for an activation of LXR, and indeed detected an increase in utg1a3, a bile conjugating enzyme with a proposed role in cholesterol elimination $[61,62]$. Interestingly, a tendency for facilitated biliary clearance has been measured in miRNA-122 knock-out mice, however there was a low treatment number in the study and a statistical difference was not detected [30]. The observed increase in $l x r$ and putative activity of LXR may be related to the observed hyperglycemia, since some studies implicate LXR as a glucose sensor, which binds glucose with similar affinity as oxysterols [63]. Similar to the previously discussed metabolic markers, time course studies are needed to delineate potential time-specific effects from true species-specific differences for the regulation of genes implicated in cholesterol metabolism. For example, while the expression of several genes implicated in cholesterol biosynthesis was decreased $1 \mathrm{~d}$ following the last injection of LNA-122i in mice, this effect was not observed $1 \mathrm{wk}$ following the last injection of LNA-122i, in spite of a stably maintained decrease in plasma cholesterol concentrations [11].

\section{Conclusion and future perspectives}

Inhibition of miRNA-122 in rainbow trout results in metabolic changes that are qualitatively similar to changes observed in mammalian models. However, quantitative differences, for example in postprandial glucose concentrations, may represent species-specific differences, which appear to be more pronounced in trout compared to previous mammalian studies. Mechanistically, the increased hyperglycemia does not appear to be related to hepatic glucose supply, favoring the hypothesis of decreased hepatic glucose utilization. Indeed, the signature of specific components, notably reductions in liver $g k$ expression, as well as reduction of hepatic FAS protein abundance, are in line with the proposed hypothesis that miRNA-122 regulates glucose homeostasis via modulation of glycolytic flux towards de novo lipogenesis. The regulation of these genes appears to be independent of the insulin signaling pathway, and is likely related to as of yet unidentified direct targets. Our in silico analysis of predicted miRNA-122 targets in trout revealed a strong enrichment for cell cycle, proliferation and differentiation processes. Given that these miRNA122 targets are conserved between trout and mice, and that cell-cycle regulators are proposed to cross-talk with metabolic pathways [64], genes involved in this group may be good candidates for mediating metabolic effects. As well, predicted miRNA-122 targets in trout were enriched for functions in glucose metabolism (insulin growth factor 2, igf2; atrial natiuretic peptide, anp; interleukin-15 receptor alpha chain, il15ra; uncoupling protein 2, ucp2; glucose transporter 1a, glut1a; growth hormone 2, gh2; cellular differentiation marker 80, cd80; suppressor of cytokine signaling 6, socs6), a result that may indicate direct regulation of glucose metabolism by miRNA-122 in trout. However, the distinct roles of these genes in trout have not been characterized with regard to glucose metabolism, but present an interesting avenue for future study. While our study is the first to characterize metabolic effects of the conserved miRNA122 in a non-mammalian vertebrate, future detailed time-course studies are needed to fully differentiate between true species-specific differences, and timedependent effects of miRNA-122 action, especially given that the metabolic functions of miRNA-122 have been shown to underlie circadian regulation in mammals [65]. 


\section{Methods \\ In silico approaches \\ Analysis of pre-miR-122 sequences in fish and vertebrate genomes}

Sequences of miRNA-122 were obtained by BLAST analysis of the zebrafish pre-miRNA-122 genome sequence against genome sequences available in the ENSEMBL database (www.ensembl.org). Following this approach we retrieved pre-miRNA-122 sequences from the African clawed frog (Xenopus leavis) [ENSXETG00000028985], the Carolina anole (Anolis carolinensis) [ENSACAT00000018998], the red jungle fowl (Gallus gallus [ENSGALG00000018343], the human (Homo sapiens) [ENSG00000207778], the field mouse (Mus musculus) [ENSMUSG00000065402], the West Indian ocean coelacanth (Latimeria chalumnae) [JH127895.1 9514 to $9584(+)$ ], the Atlantic cod (Gadhus morua) [contig56666 645 to $717(+)$ ], the green spotted puffer (Tetraodon nigroviridis) [ENSTNIT00000023441], the fugu (Takifugu rupipres) [ENSTRUG00000018785], the three-spined stickleback (Gasterosteus aculeatus) [group XIV 3950425 to 3950502 (+)], the Japanese rice fish (Oryzias latipes) [ENSORLG00000020901] and the common platy (Xiphophorus maculatus) [JH556689.1 363573 to $363653(+)$ ]. The same approach was taken for the elephant shark (Callorhinchus milii) [AAVX01098255.1] using the elephant shark genome project (http://catfishgenome.imcb. astar.edu.sg), the catfish (Ictalurus punctatus) [FI859091], using the catfish genome database (www.catfishgenome. org/catfish/cbarbel), the Atlantic salmon (Salmo salar), using the salmon database (http://genomicasalmones.dim. uchile.cl) [AGKD01016205.1 and AGKD01081167.1], the rainbow trout, using the INRA rainbow trout genome resources (Y. Guiguen, personal communication), and the gilthead sea bream (Sparus aurata) [AM950993.p.sb.5], using the INRA Sigenae database (www.sigenae.org), respectively. The genomic pre-miRNA-122 sequences were aligned using ClustalW2 (www.ebi.ac.uk/Tools/msa/ clustalw2).

\section{Prediction of omy-miR-122 mRNA targets}

Compared to species whose genomes have been completely assembled and annotated, predictions of miR-122 binding sites in 3'UTRs of rainbow trout suffer from the caveat that only a limited number of 3'UTRs have been published in rainbow trout. This problem is exacerbated by the presence of teleost genome duplications, resulting in a higher number of protein-coding genes compared to higher vertebrates [66]. Nevertheless, since miRNAtarget relationships may undergo substantial speciesspecific evolutionary changes [67], we obtained available annotated rainbow trout 3'UTR sequences $(n=1059)$ from the UTR database (www.utrdb.ba.itb.cnr.it), in order to assure a species-specific target prediction. Of the retrieved annotated rainbow trout 3'UTRs, we selected sequences that contained a perfect seed match ( $\mathrm{n}=83$ ) corresponding to nucleotides $2-7$ of the $m i R N A-122$. This approach was chosen, since the sequence of miRNA-122 is completely conserved in vertebrate evolution (Figure 1), implicating the same seed is functional in trout as in mammals. In studies using mammalian models, a 2-3 fold enrichment for this sequence motif has been shown in the 3'UTRs of upregulated mRNA following miRNA-122 inhibition $[9,11]$, and, similarly, in the 3'UTR of mRNA transcripts corresponding to identified upregulated proteins following miRNA-122 inhibition [31]. To gain insight into the potential functional roles of these predicted targets in rainbow trout, we identified human homologous sequences using Uniprot ID (www.uniprot.org/). This approach resulted in the successful mapping of 76 predicted rainbow trout target genes to mammalian homologs. Based on these identified mammalian homologs, a sub-network enrichment analysis (SNEA) was performed in Pathway Studio 9.0 (Ariadne, Rockville, MD, USA) and ResNet 9.0. SNEA was performed to identify gene networks that were significantly enriched with whose mRNAs contained predicted miRNA-122 target sites. Briefly, SNEA builds sub-networks starting from a central seed from molecular relationships (e. g., expression or binding). These data are retrieved from the ResNet 9 database, which is compiled by Ariadne using the MedScan database. The MedScan database contains over 20 million PubMed abstracts and approximately $900 \mathrm{~K}$ full-text articles. This is followed by a statistical comparison between the sub-network and a background distribution of known gene networks using a Mann-Whitney U-Test, generating a $\mathrm{p}$-value that indicates the statistical significance of the difference between these two distributions (additional details on the method can be found in the technical bulletin p. 717 from Pathway Studios 7.0). The enrichment $p$-value was set at $p<0.05$. This approach has been previously applied for the identification of gene and protein networks in teleost fishes $[68,69]$.

\section{Fish and experimental design}

The experiments were carried out in accordance with the clear boundaries of EU legal frameworks, specifically those relating to the protection of animals used for scientific purposes (i.e. Directive 2010/63/EU), and under the French legislation governing the ethical treatment of animals (Decret no. 2001-464, May 29th, 2001). The investigators carrying out the experiment had "level 1" or "level 2" certification, bestowed by the Direction Départementale des Services Vétérinaires (French vetinary services) to carry out animal experiments (INRA 2002-36, April 14th, 2002). The experiment was conducted at INRA facilities in Donzaq, certified for animal services under the permit number A64.495.1 by the French 
vetinary services, which is the competent authority. Trout eggs were incubated until hatching and alevins reared in $8^{\circ} \mathrm{C}$ stream water at the INRA experimental facility in Les Athas, France. Once fish reached the juvenile stage, animals were transferred to the INRA experimental facility at Donzacq, France, where they were maintained in $18^{\circ} \mathrm{C}$ oxygenated spring water. Juvenile trout $(n=6)$ with an average weight of $20 \mathrm{~g}$ were distributed in three $50 \mathrm{l}$ tanks and subjected to 3 intraperitoneal (i.p.) injections per week of either teleost physiological saline $(0.6 \%)$, or $12.5 \mu \mathrm{g} / \mathrm{g}$ and $25 \mu \mathrm{g} / \mathrm{g}$ body weight of LNA-122i (Locked Nucleic Acid miRNA-122 inhibitor; Exiqon, Vedbæk, Denmark) respectively, dissolved in physiological saline (Figure 10). The LNA-122i is an oligonucleotide with the specific sequence $5^{\prime}$ ATTGTCACACTCC 3' which contains phosphorothioate backbones to improve in vivo stability and distribution [70]. A short (13 nt) LNA-122i was chosen to inhibit all described rainbow trout miRNA-122 isomiRNAs. In addition to the completely conserved omy-miRNA-122 identified from trout genomic sequences (Figure 1), additional isomiRNAs sharing the same functional seed sequence, but differing in their 3'nucleotides have been identified through next generation sequencing in trout, likely resulting from posttranscriptional modification of the primary transcript [13]. Therefore, in an effort to inhibit all omy-miRNA-122 isomiRNAs, an inhibitor was chosen which contains the reverse complement of the seed region (nucleotides 2-7 of all identified omy-miRNA-122 isomiRNAs, but does not discriminate between alternate 3 ' nucleotide sequences. Trout were not fed prior to injections and, following the last injection, rainbow trout were fed ad libitum in the morning and evening for 4 days. On the fifth day, fish were fed in the morning and sacrificed four hours after the meal, and liver tissue was collected and flash frozen in liquid nitrogen and subsequently stored at $-80^{\circ} \mathrm{C}$ until further analysis. This postprandial timeframe for the experimental protocol was based on previous studies in rainbow trout, that had revealed a postprandial increase in hepatic expression of omy-miRNA-122b isomiRNA in rainbow trout $4 \mathrm{~h}$ after feeding [14], in addition to activation of the hepatic insulin pathway and regulation of metabolic gene expression. The number and doses of the LNA-122i injections were based on previous studies in mice [11], which revealed functional inhibition of miRNA-122 and associated metabolic effects at doses between $12.5 \mu \mathrm{g} / \mathrm{g}$ and $25 \mu \mathrm{g} / \mathrm{g}$ up to one week after the last injection.

\section{Plasma metabolic profile}

Plasma glucose (Glucose RTU, BioMérieux, Marcy l' Etoile, France), triglycerides (PAP 150, BioMérieux), free fatty acids (NEFA C kit, Wako Chemicals, Neuss,
Germany), and cholesterol (Cholesterol RTU, BioMérieux) concentrations were determined using commercial kits adapted to a microplate format, according to the recommendations of the manufacturer.

\section{Total RNA extraction and cDNA synthesis}

Relative hepatic gene expression was determined by quantitative real-time RT-PCR. The extraction of total RNA was performed using the Trizol reagent (Invitrogen, Carlsbad, CA, USA) according to the manufacturer's instructions. An amount of $1 \mu \mathrm{g}$ of total RNA was used for cDNA synthesis. The NCode $^{\text {ru }}$ VILO $^{\text {mm }}$ miRNA cDNA synthesis kit (Invitrogen), or the SuperScript III RNAse H- Reverse transcriptase kit (Invitrogen) with random primers (Promega, Charbonniéres, France), were used to synthesize cDNA ( $n=6$ for each treatment) for miRNA and mRNA, respectively.

\section{Real-time RT PCR}

For gene expression assays, forward primer sequences for miRNAs were taken directly from the sequence information provided by Salem and colleagues [13], or, if not available, designed based on miRNA sequences found in the trout genome. The universal reverse primer used for all miRNA expression analysis was provided by the manufacturer with the $\mathrm{NCode}^{\mathrm{ma}} \mathrm{VILO}^{\mathrm{mm}}$ miRNA cDNA synthesis kit (Invitrogen). The primer sequences used in the real-time RT-PCR assays for miRNAs and metabolic genes, as well as the conditions of the assays have been previously described [14,40,58,71]. For gene targets that had not been previously validated, primer sequences, specific assay conditions and available accession numbers from Genebank (www.ncbi.nlm.nih.gov/ genbank) or the INRA trout EST database SIGENAE (www.sigenae.org) are shown in Table 2. For real-time RT-PCR assays of miRNAs, the Roche Lightcycler 480 system was used (Roche Diagnostics, Neuilly-sur-Seine, France). The assays were performed using a reaction mix of $6 \mu \mathrm{l}$ per sample, consisting of $2 \mu \mathrm{l}$ of diluted cDNA template, $0.12 \mu \mathrm{l}$ of each primer $(10 \mu \mathrm{M}), 3 \mu \mathrm{l}$ Light Cycler $480 \mathrm{SYBR}^{\circ}$ Green I Master mix, and $0.76 \mu \mathrm{l}$ DNAse/RNAse free water (5 Prime $\mathrm{GmbH}$, Hamburg, Germany). The PCR protocol was initiated at $95^{\circ} \mathrm{C}$ for 10 min for initial denaturation of the cDNA and hotstart Taq-polymerase activation, followed by 45 cycles of a two-step amplification programme $\left(15 \mathrm{~s}\right.$ at $95^{\circ} \mathrm{C} ; 40 \mathrm{~s}$ at $60-64^{\circ} \mathrm{C}$ ), according to the primer set used. Melting curves were systematically monitored (temperature gradient at $1.1^{\circ} \mathrm{C} / 10 \mathrm{~s}$ from $65-94^{\circ} \mathrm{C}$ ) at the end of the last amplification cycle to confirm the specificity of the amplification reaction. Each PCR assay included replicate samples (duplicate of reverse transcription and PCR amplification, respectively) and negative controls (reverse transcriptase- and cDNA template-free samples). 
The gene expression assays used for protein-coding genes have been described previously [14]. As for omymiRNA SYBR Green assays, melting curves were systematically monitored (temperature gradient at $0.5^{\circ} \mathrm{C}$ / $10 \mathrm{~s}$ from $55-94^{\circ} \mathrm{C}$ at the end of the last amplification cycle), to confirm the specificity of the amplification reaction. Each PCR run included replicate samples and controls as described above. The specificity of reactions used to amplify previously uncharacterized amplicons was further confirmed by sequencing of the PCR product (Beckman-Coulter, Hope End Takeley, Essex, UK), followed by a BLAST search of the obtained sequences (http://blast.ncbi.nlm.nih.gov/Blast.cgi). For the expression analysis of miRNA and mRNA, relative quantification of target gene expression was performed using gene expression values of $u 6$ and ef $1 \alpha$ for the normalization of measured hepatic miRNAs and mRNAs, respectively, as neither gene expression values changed significantly between treatment groups (data not shown). In all cases, PCR efficiency (E) was measured by the slope of a standard curve using serial dilutions of cDNA and PCR efficiency values ranged between 1.8 and 2.2, corresponding to $90-110 \%$ efficiency.

\section{Western blotting}

Frozen liver samples ( 300 mg) were homogenized on ice with an Ultraturrax homogenizer (IMLAB Sarl, Lille, France). During homogenization, samples were kept in a buffer containing $150 \mathrm{mmol} \mathrm{l}^{-1} \mathrm{NaCl}, 10 \mathrm{mmol} \mathrm{l}^{-1}$ Tris, $1 \mathrm{mmol} \mathrm{l}^{-1}$ EGTA, $1 \mathrm{mmol} \mathrm{l}^{-1}$ EDTA (pH 7.4), 100 mmol $\mathrm{l}^{-1}$ sodium fluoride, $4 \mathrm{mmol} \mathrm{l}^{-1}$ sodium pyrophosphate, $2 \mathrm{mmol} \mathrm{l}^{-1}$ sodium orthovanadate, 1\% (v/v) Triton X-100, $0.5 \%(\mathrm{v} / \mathrm{v})$ NP40-IGEPAL, and a protease inhibitor cocktail (Roche, Basel, Switzerland). Homogenates were centrifuged at $1000 \mathrm{~g}$ for $30 \mathrm{~min}$ at $4^{\circ} \mathrm{C}$, and supernatants were then centrifuged for $45 \mathrm{~min}$ at 15.000 g. The resulting supernatants $(n=6$ for each time point) were stored at $-80^{\circ} \mathrm{C}$. Protein concentrations were determined using the Bio-Rad Protein assay kit (BIORAD, Hercules, CA, USA). According to the protein, quantities of 5-20 $\mu$ g protein per sample were subjected to SDS-PAGE and Western Blotting, using the appropriate antibodies. All primary antibodies used for analysis of the insulin signaling pathway were obtained from Cell Signaling technologies (Ozyme, Saint Quentin Yvelines, France), while antibodies used for the measurement of GK, and FAS were obtained from Santa Cruz Biotechnology (Santa Cruz, CA, USA). All antibodies have been shown to cross-react successfully with rainbow trout proteins of interest [21,40,50,72,73]. All primary antibodies used were raised in rabbit, and after final washing, membranes were incubated with an IRDye infrared secondary anti-rabbit antibody raised in goat (LI-COR Inc. Biotechnology, Lincoln, NE, USA). Bands were visualized and quantified by Infrared fluorescence using the Odyssey ${ }^{\circ}$ Imaging System (LI-COR Inc. Biotechnology, Lincoln, NE, USA).

\section{Statistical analysis}

Data were analyzed by univariate ANOVA. In cases where data were nonparametric or not homoscedastic, data transformations were used to meet ANOVA criteria. Normality was assessed using the Shaprio-Wilk test, while homoscedasticity was determined using Levene's test. Following univariate ANOVA analysis, The Student-Newman-Keuls test was used for post-hoc analysis. Data were analysed using the $\mathrm{R}$ software/R Commander package.

\section{Additional file}

Additional file 1: In silico prediction of omy-miRNA-122 regulated mRNA targets.

\section{Competing interests}

The authors declare that they have no competing interests.

\section{Authors' contributions}

JAM, SP, IS, SS designed the study. JAM retrieved genomic pre-mir-122 sequence data and rainbow trout UTR data. JAM performed pre-miRNA-122 sequence alignments and CJM performed the in silico analysis of predicted miRNA-122 trout target genes. JAM performed the metabolite, real-time RT-PCR and Western Blot analyses. Statistical analysis of data was performed by JAM, with the exception of the in silico analysis of enriched pathways, which was performed by CJM. JAM wrote the manuscript. All authors read and approved the final manuscript.

\section{Acknowledgements}

The authors would like to acknowledge Frederic Terrier and Franck Sandres at the INRA Experimental facility at Donzaq, France for animal husbandry and expert technical assistance. Alexandre Herman at INRA St.Pée-sur-Nivelle for assistance in metabolite analysis. Amélie Juanchich and Yann Guiguen at INRA Rennes for the in silico extraction of pre-miRNA-122 sequences from the trout genome. The following funding sources are equally gratefully acknowledged: A Marie Curie PDF to Jan A. Mennigen (Project Reference No. 273840, Seventh Framework Programme of the European Commission, www. cordis.europa.eu), and a NSERC Discovery Grant to CJM.

\section{Author details}

${ }^{1}$ Institut National de la Recherche Agronomique (INRA), Nutrition, Metabolism and Aquaculture Unit (UR1067), Saint-Pée-sur-Nivelle F-64310, France. ${ }^{2}$ Canadian Rivers Institute and Department of Biology, University of New Brunswick, Saint John, NB E2L 4 L5, Canada.

Received: 20 October 2013 Accepted: 22 January 2014 Published: 27 January 2014

\section{References}

1. Lee RC, Feinbaum RL, Ambros V: The C. elegans heterochronic gene lin-4 encodes small RNAs with antisense complementarity to lin-14. Cell 1993, 75:843-854.

2. Janas MM, Novina CD: Not lost in translation: stepwise regulation of microRNA targets. EMBO J 2012, 31:2446-2447.

3. Lim LP, Glasner ME, Yekta S, Burge CB, Bartel DP: Vertebrate microRNA genes. Science 2003, 299:1540.

4. Lagos-Quintana M, Rauhut R, Yalcin A, Meyer J, Lendeckel W, Tuschl T: Identification of tissue-specific microRNAs from mouse. Curr Biol 2002, 12:735-739. 
5. Laudadio I, Manfroid I, Achouri Y, Schmidt D, Wilson MD, Cordi S, Thorrez L, Knoops L, Jacquemin P, Schuit F, Pierreux CE, Odom DT, Peers B, Lemaigre FP: A feedback loop between the liver-enriched transcription factor network and miR-122 controls hepatocyte differentiation. Gastroenterology 2012, 142:119-129.

6. Jung CJ, lyengar S, Blahnik KR, Ajuha TP, Jiang JX, Farnham PJ, Zern M: Epigenetic modulation of miR-122 facilitates human embryonic stem cell self-renewal and hepatocellular carcinoma proliferation. PloS one 2011, 6:e27740.

7. Xu H, He JH, Xiao ZD, Zhang QQ, Chen YQ, Zhou H, Qu LH: Liver-enriched transcription factors regulate microRNA-122 that targets CUTL1 during liver development. Hepatology 2010, 52:1431-1442.

8. Doddapaneni R, Chawla YK, Das A, Kalra JK, Ghosh S, Chakraborti A: Overexpression of microRNA-122 enhances in vitro hepatic differentiation of fetal liver-derived stem/progenitor cells. J Cell Biochem 2013, 114:1575-1583.

9. Krutzfeldt J, Rajewsky N, Braich R, Rajeev KG, Tuschl T, Manoharan M, Stoffel M: Silencing of microRNAs in vivo with 'antagomirs'. Nature 2005, 438:685-689.

10. Esau C, Davis S, Murray SF, Yu XX, Pandey SK, Pear M, Watts L, Booten SL, Graham M, McKay A, Subramaniam A, Propp S, Lollo BA, Freier S, Bennett CF, Bhanot S, Monia BP: miR-122 regulation of lipid metabolism revealed by in vivo antisense targeting. Cell Metab 2006, 3:87-98.

11. Elmen J, Lindow M, Silahtaroglu A, Bak M, Christensen M, Lind-Thomsen A, Hedtjarn M, Hansen JB, Hansen HF, Straarup EM, McCullagh K, Kearney P, Kauppinen S: Antagonism of microRNA-122 in mice by systemically administered LNA-antimiR leads to up-regulation of a large set of predicted target mRNAs in the liver. Nucleic Acids Res 2008, 36:1153-1162.

12. Girard M, Jacquemin E, Munnich A, Lyonnet S, Henrion-Caude A: miR-122, a paradigm for the role of microRNAs in the liver. $J$ Hepatol 2008, 48:648-656

13. Salem M, Xiao C, Womack J, Rexroad CE 3rd, Yao J: A microRNA repertoire for functional genome research in rainbow trout (Oncorhynchus mykiss). Mar. Biotechnol. (NY) 2010, 12:410-429.

14. Mennigen JA, Panserat S, Larquier M, Plagnes-Juan E, Medale F, Seiliez I, Skiba-Cassy S: Postprandial regulation of hepatic microRNAs predicted to target the insulin pathway in rainbow trout. PloS one 2012, 7:e38604

15. Mennigen JA, Plagnes-Juan E, Figueiredo-Silva C, Seiliez I, Panserat S, Skiba-Cassy S: Acute endocrine and nutritional co-regulation of the hepatic omy-miRNA-122b and the lipogenic gene fas in rainbow trout, Oncorhynchus mykiss. J Comp Physiol B 2014, 169:16-24.

16. Jopling C: Liver-specific microRNA-122: biogenesis and function. RNA Biol 2012, 9:137-142.

17. Polakof $S$, Panserat $S$, Soengas JL, Moon TW: Glucose metabolism in fish: a review. J Comp Physiol B 2012, 182:1015-1045.

18. Skiba-Cassy S, Lansard M, Panserat S, Medale F: Rainbow trout genetically selected for greater muscle fat content display increased activation of liver TOR signaling and lipogenic gene expression. Am J Physiol Regul Integr Comp 2009, 297:1421-1429.

19. Kamalam BS, Medale F, Kaushik S, Polakof S, Skiba-Cassy S, Panserat S: Regulation of metabolism by dietary carbohydrates in two lines of rainbow trout divergently selected for muscle fat content. J Exp Biol 2012, 215:2567-2578.

20. Panserat S, Skiba-Cassy S, Seiliez I, Lansard M, Plagnes-Juan E, Vachot C, Aguirre P, Larroquet L, Chavernac G, Medale F, Corraze G, Kaushik S, Moon TW: Metformin improves postprandial glucose homeostasis in rainbow trout fed dietary carbohydrates: a link with the induction of hepatic lipogenic capacities? Am J Physiol Regul Integr Comp 2009, 297:707-715.

21. Polakof S, Medale F, Larroquet L, Vachot C, Corraze G, Panserat S: Regulation of de novo hepatic lipogenesis by insulin infusion in rainbow trout fed a high-carbohydrate diet. J Anim Sci 2011, 89:3079-3088.

22. Cowley DJ, Sheridan MA: Insulin stimulates hepatic lipogenesis in rainbow trout, Oncorhynchus mykiss. Fish Physiol Biochem 1993, 11:421-428.

23. Brauge C, Corraze G, Médale F: Effects of dietary levels of carbohydrate and lipid on glucose oxidation and lipogenesis from glucose in rainbow trout, Oncorhynchus mykiss, reared in freshwater or in seawater. Comp Biochem Physiol 1995, 111:117-124.

24. Blasco J, Marimón I, Viaplana I, Fernández-Borrás J: Fate of plasma glucose in tissues of brown trout in vivo: effects of fasting and glucose loading. Fish Physiol Biochem 2001, 24:247-258.
25. Stenvang J, Petri A, Lindow M, Obad S, Kauppinen S: Inhibition of microRNA function by antimiR oligonucleotides. Silence 2012, 3:1.

26. Volff JN: Genome evolution and biodiversity in teleost fish. Heredity 2005, 94:280-294.

27. Rose D, Joris J, Hackermuller J, Reiche K, Li Q, Stadler PF: Duplicated RNA genes in teleost fish genomes. J Bioinform Comput Biol 2008, 6:1157-1175.

28. Yeh CY, Chung-Davidson YW, Wang H, Li K, Li W: Intestinal synthesis and secretion of bile salts as an adaptation to developmental biliary atresia in the sea lamprey. Proc Natl Acad Sci U S A 2012, 109:11419-11424.

29. Xu RR, Zhang CW, Cao Y, Wang Q: mir122 deficiency inhibits differentiation of zebrafish hepatoblast into hepatocyte. Yi Chuan 2013, 35:488-494.

30. Tsai WC, Hsu SD, Hsu CS, Lai TC, Chen SJ, Shen R, Huang Y, Chen HC, Lee CH, Tsai TF, Hsu MT, Wu JC, Huang HD, Shiao MS, Hsiao M, Tsou AP: MicroRNA-122 plays a critical role in liver homeostasis and hepatocarcinogenesis. J Clin Invest 2012, 122:2884-2897.

31. Boutz DR, Collins PJ, Suresh U, Lu M, Ramirez CM, Fernandez-Hernando C, Huang Y, Abreu Rde S, Le SY, Shapiro BA, Liu AM, Luk JM, Aldred SF, Trinklein ND, Marcotte EM, Penalva LO: Two-tiered approach identifies a network of cancer and liver disease-related genes regulated by miR-122. J Biol Chem 2011, 286:18066-18078.

32. Desvergne $B$, Michalik $L$, Wahli W: Transcriptional regulation of metabolism. Physiol Rev 2006, 86:465-514

33. Castoldi M, Vujic Spasic M, Altamura S, Elmen J, Lindow M, Kiss J, Stolte J, Sparla R, D'Alessandro LA, Klingmuller U, Fleming RE, Longerich T, Grone HJ, Benes $V$, Kauppinen S, Hentze MW, Muckenthaler MU: The liver-specific microRNA miR-122 controls systemic iron homeostasis in mice. J Clin Invest 2011, 121:1386-1396.

34. Katoh T, Sakaguchi Y, Miyauchi K, Suzuki T, Kashiwabara S, Baba T: Selective stabilization of mammalian microRNAs by 3 ' adenylation mediated by the cytoplasmic poly(A) polymerase GLD-2. Genes Dev 2009, 23:433-438.

35. Ameres SL, Zamore PD: Diversifying microRNA sequence and function. Nat Rev Mol Cell Biol 2013, 14:475-88.

36. Sifuentes-Romero I, Milton SL, Garcia-Gasca A: Post-transcriptional gene silencing by RNA interference in non-mammalian vertebrate systems: where do we stand? Mutat Res 2011, 728:158-171.

37. Schyth BD: RNAi-mediated gene silencing in fishes? J Fish Biol 2008, 72:1890-1906.

38. Hsu SH, Wang B, Kota J, Yu J, Costinean S, Kutay H, Yu L, Bai S, La Perle K, Chivukula RR, Mao H, Wei M, Clark KR, Mendell JR, Caligiuri MA, Jacob ST, Mendell JT, Ghoshal K: Essential metabolic, anti-inflammatory, and anti-tumorigenic functions of miR-122 in liver. J Clin Invest 2012, 122:2871-2883.

39. Pellis L, van Erk MJ, van Ommen B, Bakker GC, Hendriks HF, Cnubben NH, Kleemann R, van Someren EP, Bobeldijk I, Rubingh CM, Wopereis S: Plasma metabolomics and proteomics profiling after a postprandial challenge reveal subtle diet effects on human metabolic status. Metabolomics 2012, 8:347-359.

40. Seiliez I, Panserat S, Lansard M, Polakof S, Plagnes-Juan E, Surget A, Dias K, Larquier M, Kaushik S, Skiba-Cassy S: Dietary carbohydrate-to-protein ratio affects TOR signaling and metabolism-related gene expression in the liver and muscle of rainbow trout after a single meal. Am J Physiol Regul Integr Comp 2011, 300:733-743.

41. Iynedjian PB: Molecular physiology of mammalian glucokinase. Cell Mol Life Sci 2009, 66:27-42.

42. Dentin R, Pegorier JP, Benhamed F, Foufelle F, Ferre P, Fauveau V, Magnuson MA, Girard J, Postic C: Hepatic glucokinase is required for the synergistic action of ChREBP and SREBP-1c on glycolytic and lipogenic gene expression. J Biol Chem 2004, 279:20314-20326.

43. Ferre $T$, Riu E, Bosch F, Valera A: Evidence from transgenic mice that glucokinase is rate-limiting for glucose utilization in the liver. FASEB 1996 10:1213-1218

44. O'Doherty RM, Lehman DL, Telemaque-Potts S, Newgard CB: Metabolic impact of glucokinase overexpression in liver: lowering of blood glucose in fed rats is accompanied by hyperlipidemia. Diabetes 1999 , 48:2022-2027

45. Soengas JL, Polakof S, Chen X, Sangiao-Alvarellos S, Moon TW: Glucokinase and hexokinase expression and activities in rainbow trout tissues: changes with food deprivation and refeeding. Am J Physiol Regul Integr Comp 2006, 291:810-821.

46. Panserat S, Medale F, Blin C, Breque J, Vachot C, Plagnes-Juan E, Gomes E, Krishnamoorthy R, Kaushik S: Hepatic glucokinase is induced by dietary 
carbohydrates in rainbow trout, gilthead seabream, and common carp. Am. J. Physiol. Regul. Integr. Comp. 2000, 278:1164-1170.

47. Plagnes-Juan E, Lansard M, Seiliez I, Medale F, Corraze G, Kaushik S, Panserat S, Skiba-Cassy S: Insulin regulates the expression of several metabolismrelated genes in the liver and primary hepatocytes of rainbow trout (Oncorhynchus mykiss). J Exp Biol 2008, 211:2510-2518.

48. Clarke SD, Armstrong MK, Jump DB: Nutritional control of rat liver fatty acid synthase and S14 mRNA abundance. J Nutr 1990, 120:218-224.

49. Yang YM, Seo SY, Kim TH, Kim SG: Decrease of microRNA-122 causes hepatic insulin resistance by inducing protein tyrosine phosphatase $1 \mathrm{~B}$, which is reversed by licorice flavonoid. Hepatology 2012, 56:2209-2220.

50. Dai W, Panserat S, Mennigen J, Terrier F, Dias K, Seiliez I, Skiba-Cassy S: Postprandial hepatic glycolysis and lipogenesis regulation in rainbow trout requires the activity of TORC1 signaling. J Exp Biol 2013. in press.

51. Li S, Brown MS, Goldstein JL: Bifurcation of insulin signaling pathway in rat liver: $\mathrm{mTORC} 1$ required for stimulation of lipogenesis, but not inhibition of gluconeogenesis. Proc Natl Acad Sci USA 2010, 107:3441-3446.

52. Gwinn DM, Shackelford DB, Egan DF, Mihaylova MM, Mery A, Vasquez DS, Turk BE, Shaw RJ: AMPK phosphorylation of raptor mediates a metabolic checkpoint. Mol Cell 2008, 30:214-226.

53. Peet DJ, Turley SD, Ma W, Janowski BA, Lobaccaro JM, Hammer RE, Mangelsdorf DJ: Cholesterol and bile acid metabolism are impaired in mice lacking the nuclear oxysterol receptor LXR alpha. Cell 1998, 93:693-704.

54. Zhao C, Dahlman-Wright K: Liver $\mathrm{X}$ receptor in cholesterol metabolism. J Endocrinol 2010, 204:233-240

55. Zhang Y, Breevoort SR, Angdisen J, Fu M, Schmidt DR, Holmstrom SR, Kliewer SA, Mangelsdorf DJ, Schulman IG: Liver LXRalpha expression is crucial for whole body cholesterol homeostasis and reverse cholesterol transport in mice. J Clin Invest 2012, 122:1688-1699.

56. Olkkonen VM, Lehto M: Oxysterols and oxysterol binding proteins: role in lipid metabolism and atherosclerosis. Ann Med 2004, 36:562-572.

57. Ou Z, Wada T, Gramignoli R, Li S, Strom SC, Huang M, Xie W: MicroRNA hsa-miR-613 targets the human LXRalpha gene and mediates a feedback loop of LXRalpha autoregulation. Mol Endocrinol 2011, 25:584-596.

58. Cruz-Garcia L, Sanchez-Gurmaches J, Gutierrez J, Navarro I: Role of LXR in trout adipocytes: target genes, hormonal regulation, adipocyte differentiation and relation to lipolysis. J Comp Physiol A 2012, 163:120-126.

59. Archer A, Lauter G, Hauptmann G, Mode A, Gustafsson JA: Transcriptional activity and developmental expression of liver $\mathrm{X}$ receptor (Ixr) in zebrafish. Dev Dyn 2008, 237:1090-1098.

60. Sukardi H, Zhang X, Lui EY, Ung CY, Mathavan S, Gong Z, Lam SH: Liver X receptor agonist T0901317 induced liver perturbation in zebrafish: histological, gene set enrichment and expression analyses. Biochim Biophys Acta 2012, 1820:33-43.

61. Verreault M, Senekeo-Effenberger K, Trottier J, Bonzo JA, Belanger J, Kaeding J, Staels B, Caron P, Tukey RH, Barbier O: The liver X-receptor alpha controls hepatic expression of the human bile acid-glucuronidating UGT1A3 enzyme in human cells and transgenic mice. Hepatology 2006 44:368-378.

62. Barbier O, Trottier J, Kaeding J, Caron P, Verreault M: Lipid-activated transcription factors control bile acid glucuronidation. Mol Cell Biochem 2009, 326:3-8

63. Mitro N, Mak PA, Vargas L, Godio C, Hampton E, Molteni V, Kreusch A, Saez E: The nuclear receptor LXR is a glucose sensor. Nature 2007, 445:219-223.

64. Fajas L: Re-thinking cell-cycle regulators: the cross-talk with metabolism. Front. Oncol. 2013, 3:4.

65. Gatfield D, Le Martelot G, Vejnar CE, Gerlach D, Schaad O, Fleury-Olela F, Ruskeepaa AL, Oresic M, Esau CC, Zdobnov EM, Schibler U: Integration of microRNA miR-122 in hepatic circadian gene expression. Genes Dev 2009, 23:1313-1326.

66. Howe K, Clark MD, Torroja CF, Torrance J, Berthelot C, Muffato M, Collins JE, Humphray S, McLaren K, Matthews L, McLaren S, Sealy I, Caccamo M, Churcher C, Scott C, Barrett JC, Koch R, Rauch GJ, White S, Chow W, Kilian B, Quintais LT, Guerra-Assuncao JA, Zhou Y, Gu Y, Yen J, Vogel JH, Eyre T, Redmond $\mathrm{S}$, Banerjee $\mathrm{R}$, et al: The zebrafish reference genome sequence and its relationship to the human genome. Nature 2013, 496:498-503.
67. Chen K, Rajewsky N: Deep conservation of microRNA-target relationships and $3^{\prime}$ UTR motifs in vertebrates, flies, and nematodes. Cold Spring Harb Symp Quant Biol 2006, 71:149-156.

68. Martyniuk CJ, Denslow ND: Exploring androgen-regulated pathways in teleost fish using transcriptomics and proteomics. Integr Comp Biol 2012, 52:695-704.

69. Martyniuk CJ, Alvarez S, Lo BP, Elphick JR, Marlatt VL: Hepatic protein expression networks associated with masculinization in the female fathead minnow (Pimephales promelas). J Proteome Res 2012, 11:4147-4161.

70. Levin AA: A review of the issues in the pharmacokinetics and toxicology of phosphorothioate antisense oligonucleotides. Biochim Biophy Acta 1999, 1489:69-84.

71. Polakof S, Miguez JM, Soengas JL: Dietary carbohydrates induce changes in glucosensing capacity and food intake of rainbow trout. Am J Physiol Regul Integr Comp 2008, 295:478-489.

72. Lansard M, Panserat S, Plagnes-Juan E, Seiliez I, Skiba-Cassy S: Integration of insulin and amino acid signals that regulate hepatic metabolism-related gene expression in rainbow trout: role of TOR. Amino acids 2010, 39:801-810.

73. Polakof S, Rodriguez-Alonso M, Soengas JL: Immunohistochemical localization of glucokinase in rainbow trout brain. J Comp Physiol A 2009, 153:352-358.

doi:10.1186/1471-2164-15-70

Cite this article as: Mennigen et al:: Metabolic consequences of microRNA-122 inhibition in rainbow trout, Oncorhynchus mykiss. BMC Genomics 2014 15:70.

\section{Submit your next manuscript to BioMed Central and take full advantage of:}

- Convenient online submission

- Thorough peer review

- No space constraints or color figure charges

- Immediate publication on acceptance

- Inclusion in PubMed, CAS, Scopus and Google Scholar

- Research which is freely available for redistribution
C Biomed Central 